FACULDADE DE ECONOMIA, ADMINISTRAÇÃO E CONTABILIDADE DEPARTAMENTO DE ADMINISTRAÇÃO

PROGRAMA DE PÓS-GRADUAÇÃO EM ADMINISTRAÇÃO

\author{
Desafio Aceito: \\ O Impacto do Acionista Minoritário Forte
}

Filipe Silva Ferreira

Orientador: Prof. Dr. Roy Martelanc

São Paulo 
Prof. Dr. Vahan Agopyan

Reitor da Universidade de São Paulo

Prof. Dr. Fábio Frezatti

Diretor da Faculdade de Economia, Administração e Contabilidade

Prof. Dr. Moacir de Miranda Oliveira Júnior

Chefe do Departamento de Administração

Prof. Dr. Eduardo Kazuo Kayo

Coordenador do Programa de Pós-Graduação em Administração 
Filipe Silva Ferreira

Desafio Aceito:

\title{
O Impacto do Acionista Minoritário Forte
}

\begin{abstract}
Dissertação apresentada ao Programa de Pós-Graduação em Administração do Departamento de Administração da Faculdade de Economia, Administração e Contabilidade da Universidade de São Paulo, como requisito parcial para obtenção do título de Mestre em Ciências.
\end{abstract}

Orientador: Prof. Dr. Roy Martelanc

\author{
São Paulo
}


Ficha catalográfica

Elaborada pela Seção de Processamento Técnico do SBD/FEA com os dados inseridos pelo(a) autor(a)

\section{Ferreira, Filipe.}

Desafio Aceito: O Impacto do Acionista Minoritário Forte / Filipe Ferreira. - São Paulo, 2019

$84 \mathrm{p}$.

Dissertação (Mestrado) - Universidade de São Paulo, 2019.

Orientador: Roy Martelanc.

1. Governança Corporativa. 2. Fusão e aquisição de empresas. 3. Fundo de investimento. 4. Finanças . I. Universidade de São Paulo. Faculdade de Economia, Administração e Contabilidade. II. Título. 


\section{AGRADECIMENTOS}

Primeiramente agradeço à minha família pelo apoio nos momentos de maior importância, pelo amor incondicional e pela generosa compreensão naqueles momentos em que lhes faltei e que em troca só me couberam carinho e força para seguir em frente e concluir este trabalho.

Ao meu orientador, Professor Doutor Roy Martelanc, pela confiança depositada, pelos inúmeros ensinamentos que inúmeras vezes transpassaram as barreiras da academia, pelas contribuições sem as quais este trabalho não existiria e, sobretudo, pela imensa generosidade para ir muito além de suas obrigações, oferecendo-me subsídios e referência em buscar sempre um passo adiante.

Agradeço aos membros da banca, Professora Doutora Elaine Borges, Professor Doutor Rafael Paschoarelli e Professor Doutor Rafael Noda pelas valiosas contribuições para o aperfeiçoamento deste trabalho.

Aos professores do programa de pós-graduação da FEA USP por todos os ensinamentos que me trouxeram até este ponto.

Em especial agradeço à Comdinheiro por todo o suporte oferecido a este trabalho, seja em sua atividade regular, por prover os dados quantitativos que viabilizaram do ponto de vista técnico os experimentos apresentados, seja pelo apoio e experiência de sua equipe que foram de importância singular em levar ao mundo concreto as hipóteses que restringiam-se ao imaginário.

Agradeço, pois, a todos aqueles que, ainda que indiretamente, contribuíram com este trabalho como apoio ou auxílio em minha formação. 

"Não existem métodos fáceis para resolver problemas difíceis."

René Descartes 



\section{Resumo}

A proposta deste texto, e nela mora sua maior contribuição, está em analisar o impacto dos indicadores de boas práticas de governança corporativa sobre a agressividade da empresa (mensurada pelos número de fusões e aquisições por ela propostos), a avaliação de mercado (mensurada através da relação entre valor de mercado e valor de livro) e o comportamento de investidores profissionais com relação aos papéis da empresa (mensurado pelo giro desses papéis nas carteiras dos fundos), mas oferecendo uma nova ótica a essas análises ao segregar as empresas as empresas que são objetos de pesquisa de acordo com sua estrutura societária em três categorias: sem controlador definido, com controlador definido (detentor de mais de 50\% das ações ordinárias) e minoritário desafiante (detentor de mais de $20 \%$ do capital econômico) e com controlador, mas sem desafiante.

Utilizamos dados de empresas brasileiras que tiveram suas ações listadas na B3 entre 2010 e 2017. A amostra contou com 360 empresas em 2.241 observações empresas-ano. Os resultados obtidos mostram que empresas com controlador e desafiante em sua estrutura societária e com elevado percentual de membros externos em seu conselho de administração realizam mais fusões e aquisições, e giram menos nas carteiras dos.

Palavras-chave: Governança Corporativa, Fusões e Aquisições, Fundos de Investimento 


\begin{abstract}
This study analyzes the impact of main corporate governance indicators on the aggressiveness of a company (measured by the number of mergers and acquisitions), the market valuation (the relationship between market value and book value) and on the behavior of professional investors in relation to the company's roles (measured by turning these stocks in the mutual fund portfolios), but offering a new perspective to these analyzes by segregating the companies into three groups: companies with a defined controller (holder of more than $50 \%$ of voting shares), with defined controller and challenger (holder of more than $20 \%$ of shares) and pulverized companies, segregating the companies that are objects of research according to its corporate structure separating, thus, companies with controller holding the majority of the voting capital or without this figure.
\end{abstract}

We used data from Brazilian public companies traded in B3 between 2010 and 2017. The sample had 360 companies in 2,241 observations. The results show that companies with defined controller and challenger and with a high percentage of external members in their board of directors make more mergers and acquisitions and turn less in the funds' portfolios.

Key words: Corporate Governance, Mergers and Acquisitions, Mutual Funds, 


\section{Sumário}

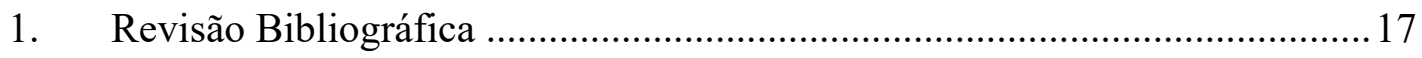

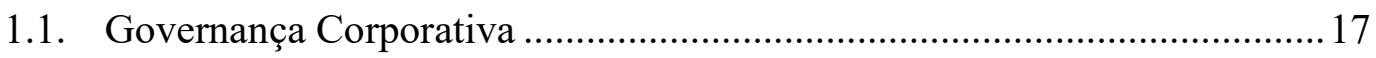

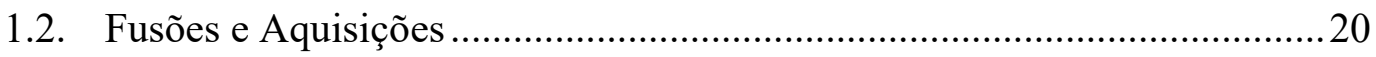

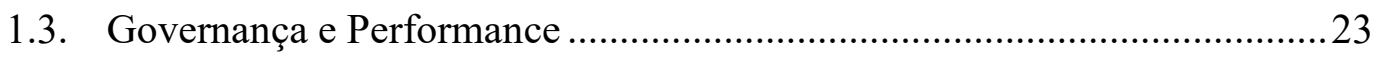

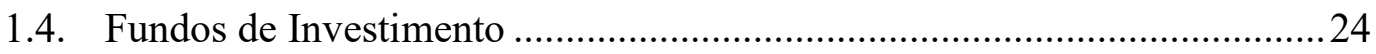

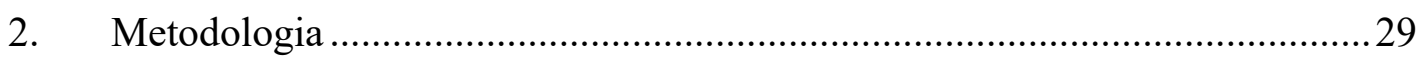

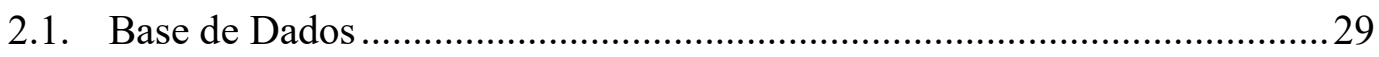

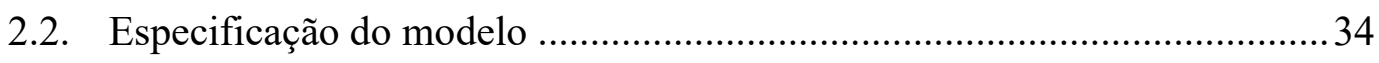

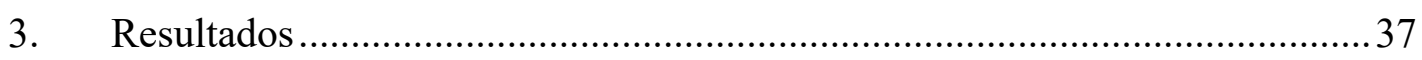

3.1. Modelo Agressividade com Fusões e Aquisições....................................... 38

3.2. Modelos de Performance .................................................................. 51

3.3. Modelos de Giro nas Carteiras dos Fundos de Investimento .......................55

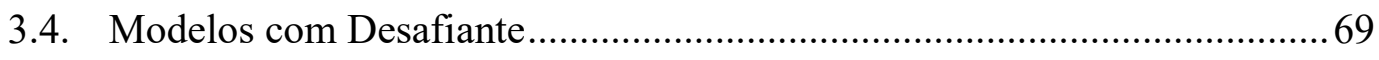

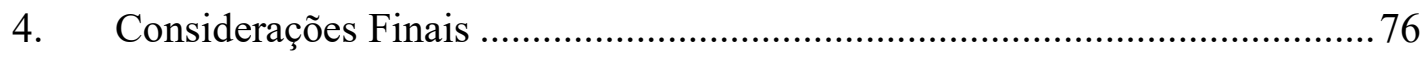

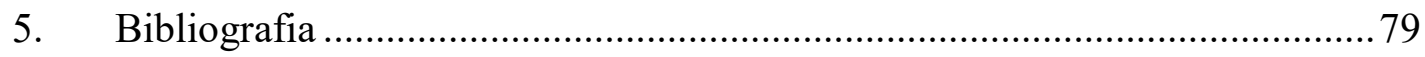




\section{Lista de Tabelas}

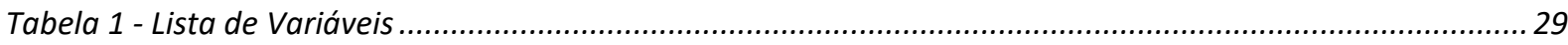

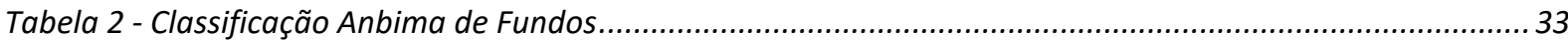

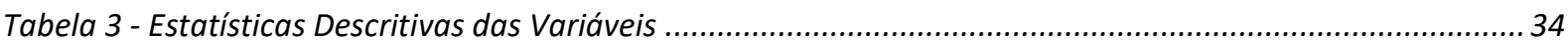

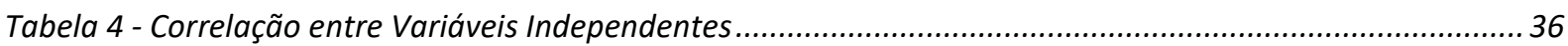

Tabela 5 - Fusões e Aquisições Todas as Empresas (ExternoEC e ExternosNEC) ........................................... 40

Tabela 6 - Fusões e Aquisições Todas as Empresas (ExternosEC) ........................................................... 41

Tabela 7 - Regressão Fusões e Aquisições Todas as Empresas (ExternosNEC) ..............................................42

Tabela 8 - Fusões e Aquisições Empresas sem Controlador Definido (ExternosEC e ExternosNEC)..................... 44

Tabela 9 - Fusões e Aquisições Empresas sem Controlador Definido (ExternosEC) .........................................45

Tabela 10 - Fusões e Aquisições Empresas sem Controlador Definido (ExternosNEC) ..................................... 46

Tabela 11 - Fusões e Aquisições Empresas com Controlador Definido (ExternosEC e ExternosNEC)...................48

Tabela 12 - Fusões e Aquisições com Empresas com Controlador Definido (ExternosEC) ..................................49

Tabela 13 - Fusões e Aquisições com Empresas com Controlador Definido (ExternosNEC)...............................50

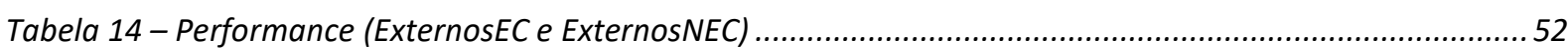

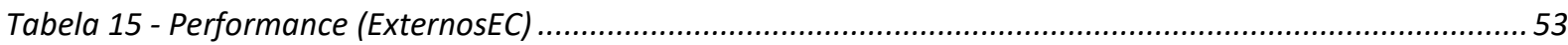

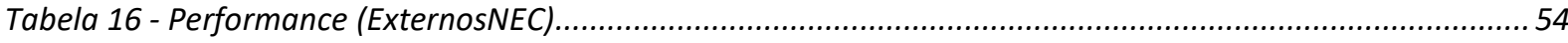

Tabela 17 - Giro dos Fundos - Todas as Empresas (ExternosEC e ExternosNEC)............................................5

Tabela 18 - Giro dos Fundos - Empresas sem Controlador (ExternosEC e ExternosNEC) .................................60

Tabela 19 - Giro dos Fundos - Empresas com Controlador (ExternosEC e ExternosNEC).................................61

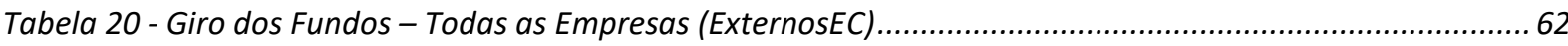

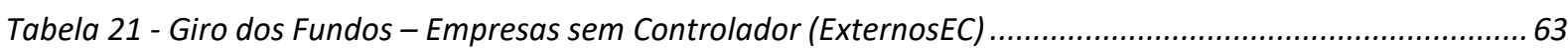

Tabela 22 - Giro dos Fundos - Empresas com Controlador (ExternosEC) ...................................................6. 64

Tabela 23 - Giro dos Fundos - Todas as Empresas (ExternosNEC) .........................................................6

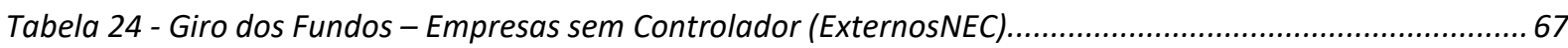

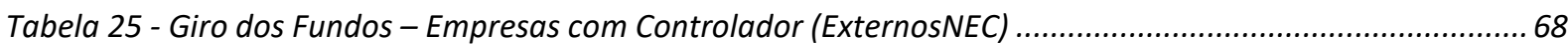


Tabela 26 - Fusões e Aquisições sem Desafiante...



Tabela 28 - Modelos de Performance Segmentados por Desafiantes ........................................................... 73



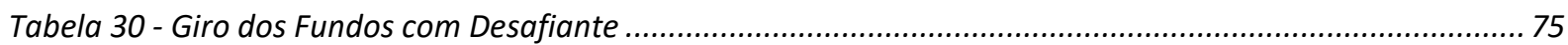




\section{Lista de Figuras}

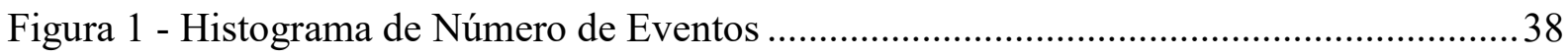

Figura 2 - Resumo das relações externos não eleitos pelo controlador e variáveis dependentes 


\section{Introdução}

Desde a evidenciação do conflito de agência originado pela segregação entre controle e gestão nos estudos de Jensen e Meckling (1976), mecanismos de controle foram amplamente disseminados numa crença quase instintiva de que se faz necessário controlar ao máximo essa lacuna impedindo, assim, a expropriação por conflito de interesses. Crença essa que, invariavelmente, não ameniza os questionamentos científicos dos pesquisadores da área de finanças que se veem constantemente em torno da questão da validade dos mecanismos de governança corporativa e do real valor oferecido por essas práticas.

Debruçados diante de dados e problemas de pesquisa alternativos, formam-se constantemente novos embates que se entrincheiram cada vez mais diante de resultados conflitantes tanto com relação a relevância desses mecanismos - se são importantes ou inertes - ou até mesmo com relação a resultados significantes apontando em uma e outra direção (Hermalin e Weisbach, 1991; Agrawal e Knoeber, 1996; Yermack, 1996; Klein, 1998; Bhagat e Black, 2002; Wintoki et al, 2012).

Dessa oscilação de resultados uma pergunta propõe-se iminente: o que faz com que a governança corporativa seja relevante a uma empresa?

Em busca da resposta a essa questão, retrocedemos ao fundamento da governança corporativa que é estabelecer controles à relação entre gestores e proprietários. Desse fundamento deriva a hipótese de que as medidas direcionadas a governança corporativa oferecerão resultados diferentes para estruturas societárias diferentes.

Para investigar essa hipótese, utilizamos três objetos de pesquisa. O primeiro deles, fusões e aquisições, está entre os eventos de maior impacto na vida das corporações. São marcos 
que mudam seus caminhos e reestruturam adquirentes e adquiridas profundamente, lançando sobre o evento todos os holofotes. Além disso, é amplamente estudado na literatura impactos pessoais da gestão na tomada de decisão que, muitas vezes, levam a destruição de valor para o acionista, seja por interesse próprio do gestor, seja por excesso de confiança, de maneira que o apetite por tais eventos se colocam por ponto focal dos interesses dos instrumentos de controle do conflito de agência, tornando-se o objeto ideal à discussão proposta, com elementos na literatura em defesa da contribuição nula na externalidade do conselho (Levi e Zhang, 2010) até a resultados positivos em valor adicionado a empresas com maior número de conselheiros externos (Kroll, 2008).

O segundo passo foi verificar a aderência do modelo proposto à avaliação da empresa através de indicadores de preço-livro e preço-lucro. Este mostra-se como um importante indicador do desempenho da empresa em multiplicar seu valor e foi objeto de diversos estudos relacionados a governança, mas com resultados igualmente variados (Agrawal e Knoeber, 1996; Bhagat e Black, 2002; Jaskiewicz, e Klein, 2007; Coles, Daniel e Naveen, 2008).

Por fim nos valemos de um dado especialmente disponível no Brasil, a carteira local de todos os fundos de investimento do país, para mensurar detalhadamente as movimentações de compras e vendas dos papéis de empresas estudadas ao longo do tempo e, dessa maneira, medir a persistência desses ativos nas carteiras de fundos ou sua característica especulativa, sinalização que com o vertiginoso crescimento desse mercado, passa a ser acompanhado de perto pelas empresas e funciona, inclusive, como instrumento de pressão sobre suas decisões (Bebchuk et al., 2017; McCahery et al., 2016).

A partir desses três grandes blocos, conseguimos indicar efeitos dos indicadores mais comuns de governança como maior agressividade por parte das empresas com maior presença de conselheiros externos eleitos pelo controlador e, simultaneamente, piores relações preço 
sobre livro. Por fim, empresas com controlador definido que apresentam CEO's ocupando simultaneamente a cadeira de presidente do conselho de administração tem menor giro na carteira dos fundos fixando-se como estratégia de longo prazo.

Os resultados encontrados são uma inflexão no estudo de governança corporativa ao sustentarem postura contrária aos manuais de governança especialmente quando em objetivo de regular o conflito entre minoritários e controladores.

A sequência deste trabalho está organizada do seguinte modo. Na seção 1 encontra-se a revisão bibliográfica e a formulação da hipótese de pesquisa, na seção 2 será discutida a metodologia e a base de dados utilizada, na seção 3 serão apresentados os resultados e a seção 4 trará as considerações finais.

\section{Revisão Bibliográfica}

\subsection{Governança Corporativa}

A separação entre propriedade e gestão estudada por Jensen e Meckling (1976) permite que os administradores não assumam o ônus financeiro de suas decisões, dissociando interesses de agente e principal. A separação entre controle e posse da empresa surge, então, como desencadeador da relação de agência.

Para reduzir os danos causados pelo problema de agência, faz-se necessário a busca por mecanismos que induzam o equilíbrio entre as partes e o alinhamento de interesses. Dos esforços e recursos empenhados nesses mecanismos são definidos os custos de agência, sendo eles os gastos gerados com o comprimento de contratos, monitoramento do agente, ineficiências burocráticas da estrutura, entre outros custos relacionados (Jensen \& Meckling, 1976). 
Shleifer e Vishny (1997) definem mecanismos de governança corporativa como sendo um conjunto de instituições legais e econômicas pelos quais fornecedores de recursos, tanto credores, quanto acionistas garantem que obterão para si o retorno sobre seu investimento.

Em se tratando de mecanismos para alinhamento de interesses de acionistas e gestores no sistema de governança corporativa de uma empresa, o Conselho de Administração é um dos principais recursos (Silveira, Barros, \& Famá, 2003). Segundo Andrade et al. (2009) o conselho de administração é percebido como um órgão cuja responsabilidade é decidir, em nome dos acionistas. Assim, o conselho de administração também se envolve no monitoramento da gestão e na definição da remuneração do pacote de executivos.

Por sua relevância, a qualidade do conselho de administração foi alvo de diversos estudos. Jensen (1993) ressalta que dentre as características mais importantes ao conselho de administração estão a não-dualidade entre CEO e presidente do conselho de administração - o que afetaria a qualidade do controle sobre o trabalho dos diretores, uma das principais atribuições do conselho de administração - e o tamanho do conselho. Nesse segundo fator o autor chama a atenção para elementos contra probatórios do conceito intuitivo de que quanto maiores forem os conselhos, melhor seu desempenho. $\mathrm{O}$ autor indica que conselhos demasiadamente numerosos impossibilitam o diálogo e prejudicam o monitoramento dos gestores.

Nas últimas duas décadas, com o aumento das atenções aos mecanismos de governança corporativa, diversos estudos têm buscado relacionar as diferentes estruturas de governança corporativa com o desemprenho da empresa ou com seu valor de mercado. Andrade et al. (2009) buscou relacionar elementos de governança corporativa como tamanho e independência do conselho de administração com o desempenho das companhias brasileiras de capital. Os autores encontraram evidências de que o conselho de administração no Brasil é maior quanto maior a 
empresa. Com relação à independência do conselho de administração e o valor de mercado das empresas, os autores constataram que a presença de conselheiros externos dentro de uma faixa ótima é percebida pelo mercado como um fator positivo. Em relação ao desempenho da empresa, o estudo apontou para uma relação positiva entre a quantidade de conselheiros e a margem operacional.

Silveira et al. (2003) utilizaram a amostra das empresas negociadas na Bolsa de Valores de São Paulo entre 1998 e 2000 para analisar a influência da presença do diretor executivo ocupando cargo de presidente do conselho da empresa, do grau de independência do conselho de administração e do tamanho do conselho no desempenho e no valor corporativo. A variável "diretor executivo como presidente do conselho" foi o indicador de governança com resultados mais importantes do estudo, apresentando um coeficiente negativo e significante estatisticamente contra as variáveis dependentes de valor Q de Tobin e valor da empresa sobre ativo total durante os três anos testados mostrando-se consistente em seus coeficientes.

De Vilhena \& Camargos (2015) utilizaram 16 empresas que mudaram voluntariamente para um nível de governança diferenciada na BM\&FBovespa entre o período de 2005 e 2011 para verificar a criação de valor e desempenho econômico-financeiro. Na mesma linha, de Oliveira Lima et al. (2015) encontraram desempenho econômico superior para empresas dos segmentos diferenciados de listagem na BM\&FBovespa.

Mais recentemente, estudos têm sido desenvolvidos buscando capturar o impacto do desenvolvimento de boas práticas de governança não apenas no valor de mercado das empresas ou no volume de seus resultados, mas em outras esferas de seus indicadores. 
Baioco (2015) indicou que a presença de um conselho fiscal permanente mostra-se relevante sobre as métricas relativas a patrimônio das empresas estudadas a partir da amostra das empresas negociadas na Bovespa entre os períodos de 2010 e 2013. Ainda de acordo com o autor, a formação em contabilidade ou em negócios dos membros do conselho fiscal afetam a qualidade dos demonstrativos contábeis. A instalação do conselho fiscal e de administração simultaneamente em uma empresa sinaliza a possibilidade de reflexos no lucro, mas o autor não identificou tempestividade o que confere alguma fragilidade a esse resultado.

Holtz et al. (2013) utilizaram uma amostra de 315 empresas ativas na BM\&FBovespa em junho de 2012 e modelos de regressão linear e regressão logística e identificaram que empresas maiores, com maior ativo intangível e mais endividadas possuem maiores conselhos de administração. Os autores defendem, ainda, que empresas com maiores fluxos de caixa operacional possuem menores conselhos de administração.

Campos Fonseca et al. (2016) estudou a relação entre indicadores de governança e a estrutura de endividamento das empresas valendo-se do Método dos Momentos Generalizado Sistêmico chegando à conclusão que a adesão aos níveis diferenciados de governança contribui para o acesso da empresa a capitais de terceiros e ao alongamento das dívidas. Gomes (2016) utilizou métricas de independência do conselho e dualidade entre CEO e presidente do conselho de administração para verificar se tais indicadores influenciam o gerenciamento tributário das empresas brasileiras.

\subsection{Fusões e Aquisições}

Fusões e aquisições estão entre os eventos de maior impacto na vida das corporações. São marcos que mudam seus caminhos e reestruturam adquirentes e adquiridas profundamente, lançando sobre o evento todos os holofotes. Nesse contexto de mais alta atenção dos principais 
executivos das organizações, poder-se-ia esperar dessas movimentações expressivos ganhos aos acionistas, no entanto, nem sempre esse benefício é verificado (Andrade, Mitchell \& Stafford, 2001).

Vem de longa data a inquietação dos pesquisadores da área de finanças em torno da variação do valor gerado mensurável das fusões e aquisições como pode ser verificado em Lubatkin (1983). E em conjunto a essa questão discute-se as possíveis causas dessas variações e o que levaria executivos a regularmente apostarem no caminho destruidor de valor.

São duas as principais linhas encontradas na literatura como motivadoras desse deságio. A primeira delas foi discutida em Jensen (1986) e pode ser resumida pelo conflito de agência que envolve a decisão de realizar ou não uma aquisição. $\mathrm{O}$ gestor poderia perceber vantagens pessoais no negócio (como maior remuneração por comandar uma organização de maior porte, menor risco de perder sua posição graças a diversificação, etc.) e optar racionalmente por agir em favor da aquisição, e assim beneficiar-se, ainda que essa decisão represente valor presente líquido negativo e, consequentemente, destrua valor aos acionistas.

A segunda linha traçada em Roll (1986), também se atenta ao executivo como centro das justificativas para essas ocorrências de destruição de valor. Sua hipótese, todavia, passa por uma irracionalidade do tomador de decisão que se sentiria demasiado confiante na capacidade de gerar valor a partir do negócio estruturado ao superestimar, por exemplo, sua habilidade como gestor e a possibilidade de expandi-la a qualquer segmento.

A partir da análise das fusões realizadas entre empresas da Forbes 500 entre 1980 e 1994, Malmendier e Tate (2008), mostraram que presidentes executivos superconfiantes comandam, na margem, negócios que destroem valor. Esses executivos tendem a sobrestimar 
sua própria capacidade de gerar retorno e, simultaneamente, tendem a acreditar que sua empresa está subavaliada no mercado o que, consequentemente, torna ainda maior a destruição de valor em negócios financiados com recursos próprios da adquirente.

Brown e Sarma (2008) investigaram a superconfiança e a influência do presidente da diretoria a partir de dados australianos e reforçaram o impacto do excesso de confiança sobre a geração de valor e afirmaram que o poder do gestor influencia, ao menos, tão negativamente quanto opção por negócios prejudiciais aos acionistas.

Mais recentemente, Huang e Kisgen (2013) aprofundaram a busca por características pessoais dos presidentes da diretoria que influenciassem na decisão por fusões e aquisições ao investigar as diferenças no valor gerado pelo negócio para empresas comandadas por executivos de gêneros diferentes e chegaram ao resultado que, na média, acordos liderados por homens tem um retorno aproximadamente $2 \%$ menor do que aqueles cuja empresa adquirente tinha um homem como presidente.

Na mesma linha, Levi, Li e Zhang (2014) mediram a influência do gênero do presidente da diretoria no número de tentativas de aquisição. A partir dos dados das empresas que compõem o S\&P 500 entre 1997 e 2009 os autores sugerem que empresas com diretoras mulheres geram $7,6 \%$ menos ofertas que empresas com presidentes homens e pagam um prêmio $15,4 \%$ menor.

No Brasil, da Silva, Kayo e Nardi (2016) investigaram a relação entre qualidade da governança corporativa e o retorno anormal das adquirentes. Os autores obtiveram evidencias de relação positiva entre o retorno anormal das adquirentes e listagem no Novo Mercado. 


\subsection{Governança e Performance}

Ao longo das últimas décadas inúmeros pesquisadores debruçaram-se diante de questões relacionadas à governança corporativa, fundamentalmente para compreender como aperfeiçoar suas práticas ao mensurar os resultados das práticas comumente propostas em validade e intensidade, levando a diversas publicações, muitas das quais divergentes entre si no que remete aos resultados encontrados.

Hermalin and Weisbach (1991) observaram o desempenho da empresa mensurado a partir do Q de Tobin e sua relação com a propriedade de ações por parte dos diretores da companhia. Os resultados encontrados caminharam no sentido de demonstrar inexistência de performance adicional para firmas com maior concentração de ações nas mãos dos diretores e, ainda que essa relação existisse, seria economicamente insignificante.

Em contrapartida, Mehran (1995) apresentou evidências de que a performance da empresa medida por ROA e Q de Tobin estaria associada positivamente com o percentual de ações detidas pelos diretores e a parcela de suas remunerações baseadas em ações, indicando haver, sim, uma relação entre composição do conselho e performance. Agrawal and Knoeber (1996) regrediram Q de Tobin contra diversas práticas de governança e encontraram relações negativas e significantes com a presença de mais membros externos no conselho de administração.

Bhagat and Black (2002) encontraram evidências de que empresas menos lucrativas aumentavam a independência de seus conselhos de administração, mas não observaram melhora representativa do desempenho após essa prática, enquanto Jaskiewicz e Klein (2007) 
apontam para efeitos negativos advindos de conselhos grandes e com muitos membros externos devido a desalinhamento e, consequentemente, novos conflitos de agência.

Coles, Daniel e Naveen (2008) encontraram uma relação em U entre tamanho do conselho e performance, indicando que conselhos muito grandes ou muito pequenos fugiriam ao ótimo. Além disso os autores evidenciaram divergências entre empresas mais ou menos complexas, o que pode justificar conselhos maiores para empresas mais diversificadas.

Defende que não há relação entre independência do conselho e performance e que resultados anteriores teriam sido obtidos devido ao viés metodológico estabelecido por problemas associados à endogeneidade estrita das variáveis independentes em relação à performance passada.

\subsection{Fundos de Investimento}

A literatura sobre a fundos inicia-se relacionada à performance da gestão ativa com Jensen (1968). O autor estuda o desempenho de 115 fundos abertos entre o período de 19451964 através do modelo estabelecido por Sharpe (1964) e não encontra diferenças significativas entre os fundos de gestão ativa e de gestão passiva em termos de retorno ajustado ao risco. Há evidências, ainda, que os gestores não são eficientes em gerar valor para cobrir o custo operacional oriundo da manutenção da estrutura do fundo de investimento.

Um passo adiante na investigação das atividades dos fundos, Gruber (1996) se propõe a investigar as motivações para a persistência do crescimento das alocações através de fundos de investimento, tendo em vista que essa decisão iria na contramão do que seria racionalmente esperado e construído pela teoria vigente de que não seria possível superar a carteira de mercado. $\mathrm{O}$ autor conclui que esse crescimento dos fundos se baseava fundamentalmente pela percepção de que parte do retorno futuro pode ser previsto pelo retorno passado dos gestores, 
de modo que investidores sofisticados conseguem reconhecer isso e investir nesses fundos com previsão de boa performance futura.

Carhart (1997) utilizou um modelo baseado em Fama e French (1996) para analisar o desempenho dos fundos de ações americanos entre julho de 1963 e dezembro de 1993. O autor identifica retorno excedente nesses portfólios, mas não atribui o resultado à qualidade da gestão e, sim, a fatores de diferenças no tamanho (valor de mercado) e momentum das empresas encarteirada, os custos de transação e impostos relacionados.

Chen et al (2000) indicaram que as ações mantidas pelos fundos de investimento não apresentam em geral performance superior ao mercado, no entanto as ações que são compradas de maneira ativa por esses fundos apresentam um retorno significativamente superior àquelas que são vendidas ativamente, o que gera um excesso de performance mensurado em $2 \%$ ao ano.

No Brasil, Rochman (2006) investigou se há benefícios em investir em fundos ativos a partir do estudo de uma amostra de 699 fundos de investimentos abertos, não exclusivos, difundidos entre 68 gestores entre 2001 e 2006. O estudo apontou indícios de que a gestão ativa gera valor para os fundos de ações e multimercados especialmente em casos de fundos de maior patrimônio e mais antigos. No caso dos fundos de renda fixa, no entanto, a indicação é contrária aos fundos ativos. Para fundos cambiais, há indícios da geração de alfa, mas não suficientes para justificar os custos relacionados.

Fonseca et al. (2007) analisaram a performance em termos de risco e retorno dos fundos de investimento no Brasil entre maio de 2001 e maio de 2006. Os autores concluíram que os retornos não apresentavam diferenças significativas entre as classes, mas ao analisar as diferenças na variância durante o período analisado os fundos de renda fixa apresentam melhor 
relação - fato associado pelos autores às elevadas taxas de juros praticadas no mercado brasileiro neste período.

Matos e Nave (2012) encontraram um retorno persistente fora do esperado sob a ótica da literatura internacional. O estudo foi elaborado considerando 68 fundos de ações no Brasil que apresentavam retorno acumulado para o período compreendido entre janeiro de 1998 e dezembro de 2009.

Matos et al. (2015) propõem um modelo de precificação linear ajustado a avaliação de fundos de investimentos em ações no Brasil e a partir de um universo de 85 fundos observados defende que apenas três deles apresentam retorno consistentemente diferenciado em relação ao mercado.

Borges e Martelanc (2015) analisaram todos os fundos disponíveis entre os anos de 2000 e 2013 com patrimônio líquido superior a R \$ 5 milhões no Brasil totalizando uma amostra de 992 fundos de investimento em ações e constataram desempenho superior ao que poderia ser esperado por distribuição probabilística (sorte). Os autores indicam que os $30 \%$ de fundos com maior patrimônio experimentaram um excesso de retorno ainda maior.

Para além das discussões a respeito da efetividade das estratégias gestoras dos fundos de investimento faz o montante por eles movimentado posicionar-se como de extrema relevância dentre os alocadores do mercado de capitais o que, naturalmente, e, consequentemente, os ofertantes de títulos observem com especial atenção esse público. Chevalier e Ellison (1997) analisaram o conflito de interesses entre empresas presentes nas carteiras dos fundos de investimento e os alocadores desses fundos refletindo sobre a divergência entre o ímpeto da empresa em buscar sua lucratividade e a demanda dos cotistas em manter equilibrada a relação entre risco e retorno de seu portfólio. Os autores evidenciaram a presença de incentivos às empresas a se adequarem a seus interesses através do 
rebalanceamento de seu portfólio entre setembro e dezembro para ajustar a composição de risco. Observou-se, então que as empresas respondem a esses incentivos e passam a levar em consideração tais preferencias em sua tomada de decisão.

A saída do fundo é vista na literatura muitas vezes como uma alternativa de controle desses investidores sobre a empresa. Segundo Hirschman (1970) seriam a "saída" e a "voz" onde o desinvestimento no papel seria um caminho para investidores que não tiveram sucesso em defender suas opiniões em relação a empresa.

Mais recentemente, McCahery et al. (2016) realizaram entrevistas para compreender melhor essa relação e as preferências dos investidores institucionais em relação a práticas de governança corporativa. A pesquisa contou com 143 respondentes dos quais $36 \%$ originários da Europa Continental, 24\% dos Estados Unidos e 16\% do Reino Unido e evidencia a importância dada pelos gestores a um conselho de administração independente.

Bebchuk et al.(2017) alerta para os conflitos de agência que podem ser gerados pela grande participação dos fundos de investimentos como acionistas relevantes nas organizações. Os autores evidenciam que especialmente em fundos passivos, o custo de um acompanhamento mais próximo da gestão seria arcado integralmente pela gestora que opta pela iniciativa, enquanto os benefícios seriam rateados igualmente entre todos os fundos de índice, o que geraria um desestímulo ao acompanhamento eficiente dessas empresas. Os Hedge Funds menores e com cobrança de taxa de performance - poderiam mitigar em algum nível esse problema.

No Brasil, de Souza Lima (2017) utilizou a carteira dos maiores fundos de pensão do país (PREVI, PETROS, FUNCEF, FUNCESP e VALIA) para investigar se as empresas 
investidas por esses fundos possuíam melhor governança, melhor desempenho e maior valor, encontrando correlações positivas entre a presença na carteira desses fundos e as três métricas utilizadas. 


\section{Metodologia}

\subsection{Base de Dados}

Os dados relativos a balanços e a indicadores de composição do conselho de administração e diretoria são com base nas informações disponíveis à público pelo empresas.NET e nos formulários de referência da Comissão de Valores Mobiliários organizados pelo Sistema Comdinheiro. Foram capturadas informações para 360 empresas ao longo do período, totalizando 2241 pares empresa-ano observados. Esses números incluem todas as empresas que tenham sido de capital aberto em qualquer momento desse período e, em decorrência disso, tenham disponibilizado seus demonstrativos financeiros ainda que tenham sua data de início posterior a 2010 ou tenham fechado capital em data que anteceda o fim do período de análise.

\section{Tabela 1 - Lista de Variáveis}

\begin{tabular}{ll}
\hline Variáveis & Definição \\
\hline $\operatorname{lnEventos}$ & $\begin{array}{l}\text { Logarítmo natural do número de fusões e aquisições propostos } \\
\text { pela empresa. } \\
\text { Logarítmo natural do número de fusões e aquisições concluídos } \\
\text { pela empresa. }\end{array}$ \\
Logarítmo natural do volume financeiro de fusões e aquisições \\
concluídos pela empresa. \\
Giro & $\begin{array}{l}\text { Soma das compras e vendas de ativos por fundos de } \\
\text { investimentos ativos dividida pela posição final do período. }\end{array}$ \\
LP & $\begin{array}{l}\text { Lucro líquido do período (indicador LL do Comdinheiro) sobre o } \\
\text { valor de mercado da empresa com 99 dias de tolerância. }\end{array}$ \\
VPAP & $\begin{array}{l}\text { Patrimônio líquido do período (indicador PL do Comdinheiro) } \\
\text { sobre o valor de mercado da empresa com 99 dias de tolerância. }\end{array}$ \\
TamCons & Número total de membros do conselho de administração. \\
Dualidade & $\begin{array}{l}\text { Se o nome do presidente do conselho de administração e do } \\
\text { presidente da diretoria forem iguais e não nulos, então 1, senão } 0 .\end{array}$
\end{tabular}




\begin{tabular}{ll} 
Variáveis & Definição \\
\hline ExternosEC & $\begin{array}{l}\text { Número de membros externos no conselho de administração } \\
\text { eleitos pelo controlador dividido pelo total de membros do } \\
\text { conselho. }\end{array}$ \\
Número de membros externos no conselho de administração não \\
eleitos pelo controlador dividido pelo total de membros. \\
O valor de mercado do ativo total dividido pelo valor contábil do \\
ativo total. O valor de mercado do ativo total é calculado como o \\
valor contábil do ativo total, menos o patrimônio líquido mais o \\
valor de mercado da empresa. \\
Lucro líquido sobre ativo total (indicador ROA no Comdinheiro). \\
ROA & $\begin{array}{l}\text { Empréstimos e financiamentos (indicador emp_fin no } \\
\text { Comdinheiro) dividido pelo ativo total (AT). }\end{array}$ \\
ENDIV & $\begin{array}{l}\text { Disponibilidades dividido por ativo total. } \\
\text { Laixa }\end{array}$ \\
Logaritmo natural do valor de mercado da empresa calculado \\
como a multiplicação do número de ações (ordinárias ou \\
preferenciais) pelo seu preço com 99 dias de tolerância. Caso não \\
haja liquidez em uma das classes é utilizado o valor da ação mais \\
líquida (função market_value no Comdinheiro). \\
1 se o percentual de ações ordinárias detido pelo maior acionista \\
dessa classe for maior que 50, senão 0.
\end{tabular}


2.2.As principais variáveis de interesse são a idade do presidente da diretoria, a presença de dualidade entre o cargo de presidente executivo e do conselho, o tamanho do conselho de administração e o grau de externalidade do conselho, medido pelo percentual de membros externos no conselho de administração segregados entre os que foram eleitos pelo controlador e os que não foram eleitos pelo controlador. Os controles para as características da empresa foram capturados de Levi, Li e Zhang (2014), Byrd e Hickman (1992), Shivdasani (1993), Martynova e Renneboog (2008), e Levi e Zhang (2010) com adaptações para a realidade brasileira. Para contornar problemas relativos a erros de publicação ou amostras não representativas, as variáveis foram winsorizadas ao nível de $5 \%$. A Erro! Fonte de referência não encontrada. apresenta as definições das variáveis e, em seguida, a Erro! Fonte de referência não encontrada. evidencia estatísticas descritivas.

Para mensurar a agressividade das empresas em ofertas, foram examinadas as Fusões e Aquisições disponíveis da base S\&P CapitalIQ entre os anos de 2010 e 2017 de empresas brasileiras em que a empresa adquirente tenha sido de capital aberto. Ao todo foram contabilizados 687 acordos no período compreendido entre as datas apontadas.

A performance das empresas teve como variáveis objeto de estudo a relação preço-livro e preço-lucro. Como fonte utilizamos, respectivamente as funções PVPA e IPL disponibilizadas na plataforma Comdinheiro com base nos cálculos originados a partir de dados disponibilizados a público através do site EMPRESAS.NET e cotações de fim de dia B3. Para ambos os casos foram utilizados 99 dias de tolerância na ausência de preço para a data especificada e em caso de ausência de liquidez em uma das classes de ações lançadas pela empresa, o preço da classe mais líquida foi considerada como como proxy em substituição, excetuando-se os casos em que 
a empresa oferece abertamente uma relação econômica diferente entre as ações. Neste caso a própria plataforma oferece o ajuste para cálculo do valor de mercado e relações derivadas.

Para evitar problemas relacionados ao viés de sobrevivência, utilizamos todos os fundos com dados de carteiras reportados ao longo da janela considerada sejam eles classificados como em funcionamento normal ou descontinuados. Os dados publicados relativos a compras, vendas e posições finais mês a mês da carteira dos fundos foram capturados e agrupados ano a ano e empresa a empresa diretamente através da ferramenta FundScreener da plataforma Comdinheiro.

Foram consideradas na análise apenas as posições e movimentações dos fundos classificados como de ações ou multimercados de acordo com a ICVM 555 e qualificados como fundo de gestão ativa pela classificação da Associação Brasileira das Entidades dos Mercados Financeiro e de Capitais (Anbima), de modo a verificar as posições que tenham sido alocadas por decisão expressa dos gestores do fundo e não pelo simples acompanhamento do índice do qual determinado papel da empresa faz parte. A tabela 2 apresenta o detalhamento da classificação Anbima.

Foram excluídos, ainda, fundos de investimento multimercado em juros e moeda por serem inaptos a operações inaptos à alocação em ativos de renda variável e de Investimento no Exterior (ações e multimercado) por terem foco em ativos estrangeiros.

Compõem a amostra as carteiras dos fundos adequados à classificação Anbima nas seguintes classes: Ações Valor/ Crescimento, Ações Dividendos, Ações Sustentabilidade / Governança, Ações Small Caps, Ações Índice Ativo, Ações Setoriais, Ações Livre e Fechado de ações; Multimercado Balanceados, Multimercado Dinâmicos, Multimercado Macro, Multimercado Trading, Multimercado Long and Short Neutro, Multimercado Long and Short Direcional, Multimercado Livre, Multimercado Capital Protegido, Multimercado Estratégia específica. 
Tabela 2 - Classificação Anbima de Fundos

\begin{tabular}{|c|c|c|}
\hline \multirow{7}{*}{ Renda Fixa } & Simples & Renda Fixa Simples \\
\hline & Indexado & Índices \\
\hline & \multirow{3}{*}{ Baixa, média, alta ou livre duração } & Soberano \\
\hline & & Grau de Investimento \\
\hline & & Crédito Livre \\
\hline & \multirow{2}{*}{ Investimento no Exterior } & Investimento no Exterior \\
\hline & & Dívida Externa \\
\hline \multirow{12}{*}{ Ações } & Indexado & Índices \\
\hline & \multirow{7}{*}{ Ativo } & Valor/Crescimento \\
\hline & & Dividendos \\
\hline & & Sustentabilidade/Governança \\
\hline & & Small Caps \\
\hline & & Índice Ativo \\
\hline & & Setoriais \\
\hline & & Livre \\
\hline & \multirow{3}{*}{ Específicos } & FMP-FGTS \\
\hline & & Fechados de Ações \\
\hline & & Mono Ações \\
\hline & Investimento no Exterior & Investimento no Exterior \\
\hline \multirow{11}{*}{ Multimercado } & \multirow{2}{*}{ Alocação } & Balanceados \\
\hline & & Dinâmicos \\
\hline & \multirow{8}{*}{ Estratégia } & Macro \\
\hline & & Trading \\
\hline & & Long and Short Neutro \\
\hline & & Long and Short Direcional \\
\hline & & \begin{tabular}{|l|} 
Juros e Moeda \\
\end{tabular} \\
\hline & & Livre \\
\hline & & Capital Protegido \\
\hline & & Estratégia específica \\
\hline & Investimento no Exterior & Investimento no Exterior \\
\hline Cambial & Cambial & Cambial \\
\hline
\end{tabular}

Elaborado pelo autor baseado em http://www.classificacaodefundos.com.br/ 


\subsection{Especificação do modelo}

Para explorar a associação entre as métricas de governança e as variáveis dependentes utilizadas por base, foram utilizados painéis de efeitos fixos cujos modelo básicos estão descritos nas equações 1-a, 1-b e 1-c:

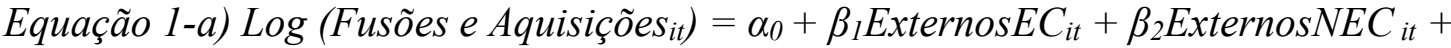
$\beta_{3}$ Idade $_{i t}+\beta_{4}$ Idade $_{i t}+\beta_{5}$ Tam Conselho $_{i t}+\beta_{6}$ Tam Conselho $_{i t}+\beta_{6}$ Dualidade $_{i t}+$ Controles $_{i t}$ $+\varepsilon_{i t}$

Equação 1-b) Performance $=\alpha_{0}+\beta_{1}$ ExternosEC $_{i t}+\beta_{2}$ ExternosNEC $_{i t}+\beta_{3}$ Idade $_{i t}+$ $\beta_{4}$ Idade $_{i t}+\beta_{5}$ TamConselho $_{i t}+\beta_{6}$ TamConselho $_{i t}+\beta_{6}$ Dualidade $_{i t}+$ Controles $_{i t}+\varepsilon_{i t}$ Equação 1-c) Giro na Carteira dos Fundos $=\alpha_{0}+\beta_{1}$ ExternosEC $_{i t}+\beta_{2}$ ExternosNEC $_{i t}+$ $\beta_{3}$ Idade $_{i t}+\beta_{4}$ Idade $_{i t}+\beta_{5}$ Tam Conselho $_{i t}+\beta_{6}$ TamConselho $_{i t}+\beta_{6}$ Dualidade $_{i t}+$ Controles $_{i t}$ $+\varepsilon_{i t}$

No qual a métrica representativa de fusões e aquisições varia entre número de eventos propostos pela empresa objeto, o número de eventos concluídos ou o volume financeiro das transações concluídas pela empresa objeto, variação que é oferecida para a verificação de robustez. Para evitar o excesso de influência de determinado ponto ao resultado final, foram aplicados logaritmos aos valores das variáveis dependentes de cada modelo com a atenção de utilizar o logaritmo dos números de eventos (propostos e concluídos) somados a um, contornando eventuais problemas decorrentes de empresas que não se envolveram em eventos no ano.

Tabela 3 - Estatísticas Descritivas das Variáveis

\begin{tabular}{lllllll}
\hline $\min$ & $\max$ & media & p25 & p75 & N \\
\hline
\end{tabular}




\begin{tabular}{lcccccc} 
ExternosEC & 0 & 1 & .62 & .48 & .818 & 3651 \\
ExternosNEC & 0 & 1 & .22 & 0 & .333 & 3651 \\
Tamdir & 2 & 10 & 4.72 & 3 & 6 & 3667 \\
Dualidade & 0 & 1 & .09 & 0 & 0 & 5576 \\
Idade & 0 & 71 & 48.37 & 43 & 59 & 3070 \\
QTOB & .65 & 5.12 & 1.57 & .92 & 1.70 & 2800 \\
ROA & -86.11 & 17.33 & -3.75 & -2.66 & 6.46 & 3704 \\
ENDIV & 0 & .64 & .24 & .01 & .39 & 3714 \\
Caixa & .001 & .68 & .15 & .03 & .19 & 3714 \\
lnMV & 16.56 & 24.16 & 20.68 & 19.15 & 22.34 & 2847 \\
GiroFundos & 0 & 24.57 & 4.52 & .52 & 5.48 & 2044 \\
lnVolume & 0 & 10.55 & .22 & 0 & 0 & 5576 \\
lnConcluidos & 0 & 2.48 & .07 & 0 & 0 & 5576 \\
lnEventos & 0 & 2.56 & .07 & 0 & 0 & 5576 \\
VPAP & -100 & 100 & .34 & .31 & 1.30 & 1817 \\
LP & -100 & 100 & -.48 & -.05 & .10 & 1812 \\
\hline
\end{tabular}

A performance é verificada pela divisão do patrimônio líquido contábil pelo valor de mercado da empresa e pela divisão do lucro líquido do período também pelo seu valor de mercado. Em ambos os casos os dados foram extraídos diretamente da plataforma de dados contábeis do Sistema Comdinheiro. 
Tabela 4 - Correlação entre Variáveis Independentes

\begin{tabular}{|c|c|c|c|c|c|c|c|c|c|c|c|c|c|c|c|c|}
\hline Variáveis & $(1)$ & (2) & (3) & $(4)$ & $(5)$ & $(6)$ & $(7)$ & (8) & $(9)$ & $(10)$ & (11) & (12) & (13) & (14) & $(15)$ & $(16)$ \\
\hline (1) ExternosEC & 1.000 & & & & & & & & & & & & & & & \\
\hline (2) ExternosNEC & -0.921 & 1.000 & & & & & & & & & & & & & & \\
\hline (3) tamdir & -0.017 & 0.036 & 1.000 & & & & & & & & & & & & & \\
\hline (4) Dualidade & -0.017 & -0.100 & -0.190 & 1.000 & & & & & & & & & & & & \\
\hline (5) Idade & -0.033 & 0.013 & -0.037 & 0.166 & 1.000 & & & & & & & & & & & \\
\hline (6) QTOB & -0.079 & 0.087 & 0.072 & -0.021 & 0.027 & 1.000 & & & & & & & & & & \\
\hline (7) $\mathrm{ROA}$ & -0.012 & 0.015 & 0.174 & -0.000 & 0.082 & 0.113 & 1.000 & & & & & & & & & \\
\hline (8) ENDIV & 0.082 & 0.005 & -0.022 & -0.110 & -0.089 & -0.097 & -0.163 & 1.000 & & & & & & & & \\
\hline (9) Caixa & 0.021 & -0.033 & 0.099 & 0.005 & 0.109 & 0.185 & 0.158 & -0.203 & 1.000 & & & & & & & \\
\hline (10) $\operatorname{lnMV}$ & 0.081 & -0.023 & 0.482 & -0.217 & 0.071 & 0.177 & 0.378 & 0.018 & 0.038 & 1.000 & & & & & & \\
\hline (11) GiroFundos & -0.006 & 0.009 & 0.099 & -0.079 & -0.002 & 0.093 & -0.077 & 0.059 & -0.078 & 0.193 & 1.000 & & & & & \\
\hline (12) lnVolume & 0.022 & 0.012 & 0.057 & -0.039 & 0.004 & 0.023 & 0.096 & 0.041 & -0.000 & 0.244 & 0.068 & 1.000 & & & & \\
\hline (13) lnConcluidos & -0.010 & 0.053 & 0.112 & -0.063 & 0.005 & 0.031 & 0.110 & 0.045 & 0.011 & 0.275 & 0.092 & 0.764 & 1.000 & & & \\
\hline (14) lnEventos & -0.011 & 0.053 & 0.119 & -0.065 & 0.009 & 0.030 & 0.113 & 0.044 & 0.008 & 0.283 & 0.104 & 0.751 & 0.987 & 1.000 & & \\
\hline (15) VPAP & -0.011 & -0.005 & 0.032 & -0.068 & -0.033 & -0.311 & 0.152 & -0.076 & 0.013 & 0.064 & -0.017 & -0.001 & 0.003 & 0.006 & 1.000 & \\
\hline (16) LP & -0.016 & 0.002 & 0.113 & -0.003 & 0.020 & 0.017 & 0.431 & -0.113 & 0.112 & 0.192 & -0.140 & 0.050 & 0.057 & 0.058 & 0.220 & 1.000 \\
\hline
\end{tabular}


Os dados relativos ao giro da carteira dos fundos de investimento referem-se à soma do montante comprado e vendido pelos fundos pertencentes ao universo analisado ao longo de cada ano dividida pela soma das posições finais dos respectivos anos desses fundos. Para alcançar esses números foram considerados os dados de compras, vendas e posições finais reportados mensalmente na carteira de investimentos disponibilizada a público. Esse dado foi, então, agrupado por empresa investida e por ano. Soma-se, então, o volume total comprado pelos fundos no período ao volume total vendido por eles nesse mesmo prazo e divide-se pela soma das posições finais da indústria nos papéis daquela companhia ao fim do ano especificado.

Estabelecido o modelo, antes de experimentá-lo, é interessante verificar a correlação entre as diversas variáveis envolvidas afim de evitar complicações advindas de multicolineatidade. A Tabela 4, evidencia a correlação entre as variáveis que comporão os modelos apresentados na seção de Resultados.

\section{Resultados}

A presente seção tem por objetivo expor, analisar e discutir os modelos elaborados com base na metodologia e arcabouço teórico verificados nas seções anteriores. Além das variáveis de governança que são o alvo fundamental deste estudo, estão presentes, também, variáveis de controle relacionadas à estrutura financeira da empresa para controlar possíveis endogeneidades. 


\subsection{Modelo Agressividade com Fusões e Aquisições}

Ao tratar com o volume de fusões e aquisições de cada empresa em cada ano, é natural se esperar que exista uma concentração de resultados nulos (zero). A Figura 1, ilustra através de um histograma a concentração do número de transações propostas pela empresa estudada.

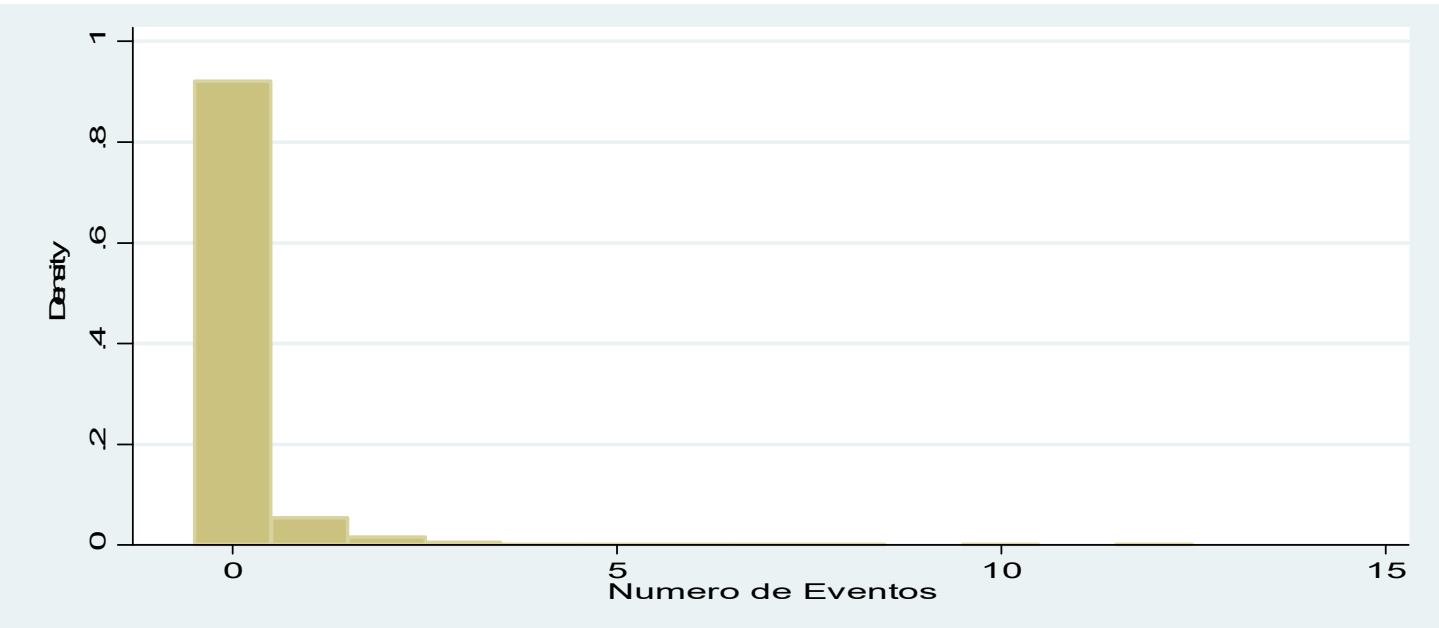

Figura 1 - Histograma de Número de Eventos

Devido à concentração de zeros verificada na variável dependente levando a variância para aproximar-se da média, utilizou-se, então, uma regressão em painel de efeitos fixos com Poisson para os modelos 4 e 5, de maneira a tornar robusto o modelo a eventuais assimetrias associadas aos casos relacionados a contagem. Para corrigir eventuais desvios associados à heterocedasticidade, foram utilizados modelos com erros padrão robustos.

Os modelos diferem entre si, em síntese, pela variável que que mensura o apetite por fusões e aquisições. Nos modelos 1 e 4, a variável dependente é o logaritmo natural de um mais o número de eventos propostos pela empresa observada. Nos modelos 2 e 5 a construção da variável é bastante semelhante, no entanto se restringe aos eventos concluídos. No terceiro modelo, por fim, é considerado o volume financeiro das 
transações concluídas. As tabelas 5, 6 e 7 apresentam os resultados obtidos a partir do conjunto amplo de dados - sem distinções associadas à estrutura societária -, a distinção verificada entre elas está na variável utilizada para mensurar a externalidade do conselho de administração. Respectivamente são utilizados o percentual de membros externos do conselho de administração eleitos pelo controlador (EleitosEC) e o percentual de membros externos não eleitos pelo controlador (EleitosNEC), apenas os membros eleitos pelo controlador, e, por fim, apenas os não eleitos pelo controlador testando, assim, a robustez do modelo à forma de mensurar esta variável dada a elevada correlação verificada entre as duas metodologias.

Na tabela 5, em todos os modelos foi verificado algum nível de significância numa associação positiva entre a maior presença de membros externos no conselho de administração e maior agressividade nas fusões e aquisições. $O$ modelo 2 aponta especificamente para um maior número de acordos concluídos quanto maior o número de membros externos no conselho de administração eleitos pelo controlador ou não a $10 \%$ de significância. O modelo 3, por outro lado, sugere maior volume financeiro transacionado para empresas com maior percentual de membros externos, mas que tenham sido eleitos pelo controlador no conselho - neste a 5\% de significância. Os modelos 4 e 5 , robustos aos problemas de excesso de zeros associados as variáveis dependentes originárias de contagem, mostram significância tanto na maior presença de membros externos eleitos pelo controlador, quanto nos eleitos pelos minoritários a $5 \%$ de significância. Os modelos 6 e 7 são complementares para verificar se o ganho de significância teria sido decorrente da subamostra utilizada pelos painéis com Poisson. Os modelos representam, então, painéis de efeitos fixos semelhantes aos modelos 1 e 2, mas restritos às amostras utilizadas com Poisson. Como é possível notar, não há ganho 
expressivo em significância quando comparados com os modelos base 1 e 2 como ocorre nos modelos 4 e 5 .

Tabela 5 - Fusões e Aquisições Todas as Empresas (ExternoEC e ExternosNEC)

\begin{tabular}{|c|c|c|c|c|c|c|c|}
\hline VARIÁVEIS & Modelo 1 & Modelo 2 & Modelo 3 & Modelo 4 & Modelo 5 & Modelo 6 & Modelo 7 \\
\hline \multirow[t]{2}{*}{ ExternosEC } & $0.117^{*}$ & $0.110^{*}$ & $0.626^{* *}$ & $1.549 * *$ & $1.596^{* *}$ & $0.356^{*}$ & $0.336^{*}$ \\
\hline & $(0.0652)$ & $(0.0638)$ & $(0.267)$ & $(0.763)$ & $(0.778)$ & $(0.184)$ & $(0.181)$ \\
\hline \multirow[t]{2}{*}{ ExternosNEC } & $0.137^{*}$ & $0.142 *$ & 0.414 & $1.663^{* *}$ & $1.750 * *$ & $0.390 * *$ & $0.391 * *$ \\
\hline & $(0.0787)$ & $(0.0770)$ & $(0.312)$ & $(0.793)$ & $(0.809)$ & $(0.191)$ & $(0.188)$ \\
\hline \multirow[t]{2}{*}{ tamdir } & -0.007 & -0.007 & -0.0190 & -0.0517 & -0.0551 & -0.0130 & -0.0136 \\
\hline & $(0.007)$ & $(0.007)$ & $(0.0319)$ & $(0.0551)$ & $(0.0573)$ & $(0.0136)$ & $(0.0135)$ \\
\hline \multirow[t]{2}{*}{ Dualidade } & 0.0474 & 0.0443 & 0.177 & 0.324 & 0.314 & 0.105 & 0.0983 \\
\hline & $(0.0320)$ & $(0.0313)$ & $(0.153)$ & $(0.215)$ & $(0.218)$ & $(0.0733)$ & $(0.0722)$ \\
\hline \multirow[t]{2}{*}{ QTOB } & $0.0261 * *$ & $0.0240 * *$ & $0.104 * *$ & -0.0313 & -0.0445 & 0.0196 & 0.0176 \\
\hline & $(0.0108)$ & $(0.0107)$ & $(0.0446)$ & $(0.0869)$ & $(0.0906)$ & $(0.0210)$ & $(0.0214)$ \\
\hline \multirow[t]{2}{*}{$\mathrm{ROA}$} & $0.001 *$ & 0.001 & $0.003 * *$ & 0.0130 & 0.0113 & $0.004^{*}$ & 0.004 \\
\hline & $(0.001)$ & $(0.001)$ & $(0.002)$ & $(0.010)$ & $(0.010)$ & $(0.002)$ & $(0.002)$ \\
\hline \multirow[t]{2}{*}{ ENDIV } & -0.00415 & -0.00766 & -0.346 & -0.142 & -0.214 & -0.000163 & -0.00857 \\
\hline & $(0.0834)$ & $(0.0819)$ & $(0.334)$ & $(0.689)$ & $(0.696)$ & $(0.180)$ & $(0.177)$ \\
\hline \multirow[t]{2}{*}{ Caixa } & -0.0101 & -0.00243 & 0.0879 & -0.00639 & 0.0513 & 0.0675 & 0.0833 \\
\hline & $(0.0781)$ & $(0.0778)$ & $(0.398)$ & $(0.653)$ & $(0.666)$ & $(0.214)$ & $(0.214)$ \\
\hline \multirow[t]{2}{*}{$\operatorname{lnMV}$} & $0.0384 * * *$ & $0.0371 * * *$ & $0.155^{* * *}$ & $0.435 * * *$ & $0.461 * * *$ & $0.0929 * * *$ & $0.0901 * * *$ \\
\hline & $(0.0120)$ & $(0.0118)$ & $(0.0533)$ & $(0.0985)$ & $(0.102)$ & $(0.0225)$ & $(0.0220)$ \\
\hline \multirow[t]{2}{*}{ Constant } & $-0.775^{* * *}$ & $-0.745^{* * *}$ & $-3.283 * * *$ & & & $-2.024 * * *$ & $-1.957 * * *$ \\
\hline & $(0.260)$ & $(0.254)$ & $(1.097)$ & & & $(0.523)$ & $(0.507)$ \\
\hline Observations & 2,535 & 2,535 & 2,535 & 1,143 & 1,137 & 1,143 & 1,143 \\
\hline R-squared & 0.018 & 0.017 & 0.016 & & & 0.044 & 0.042 \\
\hline Number of idfirma & 375 & 375 & 375 & 153 & 152 & 153 & 153 \\
\hline
\end{tabular}

Robust standard errors in parentheses

$$
* * * \mathrm{p}<0.01,{ }^{* *} \mathrm{p}<0.05,{ }^{*} \mathrm{p}<0.1
$$


Tabela 6 - Fusões e Aquisições Todas as Empresas (ExternosEC)

\section{Variáveis}

Modelo 1 Modelo 1 Modelo 3

Modelo 4

Modelo 5

Modelo 6

Modelo 7

\begin{tabular}{|c|c|c|c|c|c|c|c|}
\hline \multirow[t]{2}{*}{ ExternosEC } & 0.00790 & -0.00315 & $0.297^{*}$ & 0.0547 & 0.0273 & 0.00446 & -0.00319 \\
\hline & $(0.0515)$ & (0.0499) & $(0.171)$ & $(0.292)$ & $(0.306)$ & $(0.0894)$ & $(0.0880)$ \\
\hline \multirow[t]{2}{*}{ tamdir } & -0.00718 & -0.00742 & -0.0190 & -0.0459 & -0.0473 & -0.0126 & -0.0138 \\
\hline & $(0.00715)$ & $(0.00706)$ & $(0.0322)$ & $(0.0533)$ & $(0.0550)$ & $(0.0139)$ & $(0.0137)$ \\
\hline \multirow[t]{2}{*}{ Dualidade } & 0.0504 & 0.0474 & 0.186 & 0.352 & 0.338 & 0.118 & 0.110 \\
\hline & $(0.0322)$ & $(0.0314)$ & $(0.153)$ & $(0.216)$ & $(0.217)$ & $(0.0736)$ & $(0.072)$ \\
\hline \multirow[t]{2}{*}{ QTOB } & $0.0269 * *$ & $0.0248 * *$ & $0.106 * *$ & -0.0102 & -0.0236 & 0.0233 & 0.0224 \\
\hline & $(0.0109)$ & $(0.0109)$ & $(0.0450)$ & $(0.0853)$ & $(0.0890)$ & $(0.0211)$ & $(0.0217)$ \\
\hline \multirow[t]{2}{*}{ ROA } & $0.001^{*}$ & 0.001 & $0.003 * *$ & 0.0140 & 0.0123 & $0.004 *$ & $0.04 *$ \\
\hline & $(0.001)$ & $(0.001)$ & $(0.002)$ & $(0.010)$ & $(0.0101)$ & $(0.002)$ & $(0.002)$ \\
\hline \multirow[t]{2}{*}{ ENDIV } & -0.000478 & -0.00387 & -0.335 & -0.141 & -0.227 & 0.0234 & -0.00577 \\
\hline & $(0.0833)$ & $(0.0818)$ & $(0.333)$ & $(0.679)$ & $(0.684)$ & $(0.179)$ & $(0.176)$ \\
\hline \multirow[t]{2}{*}{ Caixa } & -0.0145 & -0.00699 & 0.0745 & -0.0440 & 0.0211 & 0.0439 & 0.0820 \\
\hline & $(0.0787)$ & $(0.0784)$ & $(0.400)$ & $(0.660)$ & $(0.674)$ & $(0.217)$ & $(0.219)$ \\
\hline \multirow[t]{2}{*}{$\operatorname{lnMV}$} & $0.0387 * * *$ & $0.0373 * * *$ & $0.156 * * *$ & $0.424 * * *$ & $0.451 * * *$ & $0.0957 * * *$ & $0.0926^{* * *}$ \\
\hline & $(0.0119)$ & $(0.0117)$ & $(0.0527)$ & $(0.100)$ & $(0.105)$ & $(0.0227)$ & $(0.0223)$ \\
\hline \multirow[t]{2}{*}{ Constant } & $-0.681 * * *$ & $-0.647 * *$ & $-2.998 * * *$ & & & $-1.769 * * *$ & $-1.697 * * *$ \\
\hline & $(0.256)$ & $(0.250)$ & $(1.143)$ & & & $(0.503)$ & $(0.494)$ \\
\hline Observations & 2,535 & 2,535 & 2,535 & 1,143 & 1,137 & 1,137 & 1,137 \\
\hline R-squared & 0.016 & 0.015 & 0.015 & & & 0.040 & 0.039 \\
\hline $\begin{array}{l}\text { Number of } \\
\text { idfirma }\end{array}$ & 375 & 375 & 375 & 153 & 152 & 152 & 152 \\
\hline
\end{tabular}

Robust standard errors in parentheses

$$
* * * \mathrm{p}<0.01, * * \mathrm{p}<0.05, * \mathrm{p}<0.1
$$


Tabela 7 - Regressão Fusões e Aquisições Todas as Empresas (ExternosNEC)

\begin{tabular}{|c|c|c|c|c|c|c|c|}
\hline \multirow[t]{2}{*}{ ExternosNEC } & 0.0309 & 0.0422 & -0.155 & 0.165 & 0.208 & 0.0677 & 0.0713 \\
\hline & $(0.0578)$ & $(0.0558)$ & $(0.194)$ & $(0.294)$ & $(0.307)$ & $(0.0903)$ & $(0.0890)$ \\
\hline \multirow[t]{2}{*}{ tamdir } & -0.007 & -0.007 & -0.0188 & -0.046 & -0.0477 & -0.0128 & -0.0140 \\
\hline & $(0.007)$ & $(0.007)$ & $(0.032)$ & $(0.053)$ & $(0.055)$ & $(0.0139)$ & $(0.0138)$ \\
\hline \multirow[t]{2}{*}{ Dualidade } & 0.0506 & 0.0473 & 0.194 & $0.359^{*}$ & 0.347 & 0.118 & 0.110 \\
\hline & $(0.0320)$ & $(0.0311)$ & $(0.153)$ & $(0.215)$ & $(0.217)$ & $(0.0727)$ & $(0.0709)$ \\
\hline \multirow[t]{2}{*}{ QTOB } & $0.0255^{* *}$ & $0.0234 * *$ & $0.101 * *$ & -0.0243 & -0.0380 & 0.0201 & 0.0193 \\
\hline & $(0.0107)$ & $(0.0107)$ & $(0.0443)$ & $(0.0869)$ & $(0.0907)$ & $(0.0214)$ & $(0.0220)$ \\
\hline \multirow[t]{2}{*}{ ROA } & $0.001 *$ & 0.001 & $0.003 * *$ & 0.0141 & 0.0123 & $0.004 *$ & $0.004 *$ \\
\hline & $(0.001)$ & $(0.001)$ & $(0.002)$ & $(0.010)$ & $(0.010)$ & $(0.002)$ & $(0.002)$ \\
\hline \multirow[t]{2}{*}{ ENDIV } & -0.00170 & -0.00537 & -0.333 & -0.128 & -0.207 & 0.0188 & -0.0104 \\
\hline & $(0.0830)$ & $(0.0815)$ & $(0.331)$ & $(0.677)$ & $(0.681)$ & $(0.179)$ & $(0.176)$ \\
\hline \multirow[t]{2}{*}{ Caixa } & -0.0166 & -0.00853 & 0.0530 & -0.115 & -0.0555 & 0.0326 & 0.0717 \\
\hline & $(0.0787)$ & $(0.0784)$ & $(0.402)$ & $(0.659)$ & $(0.673)$ & $(0.216)$ & $(0.218)$ \\
\hline \multirow[t]{2}{*}{$\operatorname{lnMV}$} & $0.0381 * * *$ & $0.0368 * * *$ & $0.154 * * *$ & $0.424 * * *$ & $0.450 * * *$ & $0.0952 * * *$ & $0.0921^{* * *}$ \\
\hline & $(0.0120)$ & $(0.0118)$ & $(0.0528)$ & $(0.101)$ & $(0.106)$ & $(0.0229)$ & $(0.0224)$ \\
\hline \multirow[t]{2}{*}{ Constant } & $-0.669 * *$ & $-0.646^{* *}$ & $-2.715^{* *}$ & & & $-1.765^{* * *}$ & $-1.702 * * *$ \\
\hline & $(0.259)$ & $(0.253)$ & (1.112) & & & $(0.511)$ & $(0.500)$ \\
\hline Observations & 2,535 & 2,535 & 2,535 & 1,143 & 1,137 & 1,137 & 1,137 \\
\hline R-squared & 0.017 & 0.016 & 0.014 & & & 0.041 & 0.040 \\
\hline $\begin{array}{l}\text { Number of } \\
\text { idfirma }\end{array}$ & 375 & 375 & 375 & 153 & 152 & 152 & 152 \\
\hline
\end{tabular}

Robust standard errors in parentheses

$$
* * * \mathrm{p}<0.01,{ }^{* *} \mathrm{p}<0.05, * \mathrm{p}<0.1
$$


As tabelas 6 e 7 não apresentaram significância aos níveis usuais para nenhuma das variáveis de interesse. Embora não exista propriamente uma incoerência entre os resultados encontrados, os modelos não se mostraram robustos em suas significâncias entre si o que justificaria a oscilação de interpretações pela literatura entre a neutralidade ou não das práticas de governança.

Em face a essa questão, voltamo-nos ao ponto de partida do debate sobre governança que foi o ponto de partida a todos os outros questionamentos, ou seja, a separação entre agente e principal. Ocorre que se as estruturas de governança são estabelecidas com o intuito de regular as relações entre diretores e acionistas - ou entre controladores e minoritários -, é natural considerarmos que seus efeitos e consequências serão relacionados à estrutura de capital da empresa objeto.

A título de exemplo, uma empresa de capital difuso em bolsa, preocupar-se-á, essencialmente, na regulação das atividades dos diretores e o risco de expropriação está nesse grupo de agentes e, consequentemente, no seu conjunto de interesses - controle de uma empresa maior, exposição, entre outros. Uma empresa com controle bem definido, por outro lado, enfrenta menos esse problema uma vez que o acionista controlador tende a acompanhar mais de perto o cotidiano da empresa, os conflitos, nesse caso, tendem a se concentrar em torno da relação entre o controlador e os minoritários.

Partindo desse racional, retomamos os testes já expostos, mas desta vez segmentando o universo das empresas estudadas em dois grupos: sem um controlador real bem definido - ou seja, sem um acionista com mais de 50\% das ações ordinárias -, e com um controlador real bem definido - empresas que tenham um acionista em sua base com mais de 50\% das ações ordinárias. 
Tabela 8 - Fusões e Aquisições Empresas sem Controlador Definido (ExternosEC e ExternosNEC)

\begin{tabular}{|c|c|c|c|c|c|c|c|}
\hline VARIÁVEIS & Modelo 1 & Modelo 2 & Modelo 3 & Modelo 4 & Modelo 5 & Modelo 6 & Modelo 7 \\
\hline \multirow[t]{2}{*}{ ExternosEC } & 0.135 & 0.108 & 0.356 & 1.372 & 1.157 & 0.366 & 0.298 \\
\hline & $(0.174)$ & $(0.172)$ & $(0.631)$ & $(2.031)$ & $(2.080)$ & $(0.441)$ & $(0.438)$ \\
\hline \multirow[t]{2}{*}{ ExternosNEC } & 0.0356 & 0.0189 & -0.154 & 0.730 & 0.523 & 0.205 & 0.153 \\
\hline & $(0.171)$ & $(0.171)$ & $(0.647)$ & $(2.059)$ & $(2.124)$ & $(0.442)$ & $(0.441)$ \\
\hline \multirow[t]{2}{*}{ tamdir } & 0.005 & 0.005 & -0.003 & 0.04 & 0.04 & 0.009 & 0.009 \\
\hline & $(0.0116)$ & $(0.0118)$ & $(0.0431)$ & $(0.0732)$ & $(0.0759)$ & $(0.0191)$ & $(0.0194)$ \\
\hline \multirow[t]{2}{*}{ Dualidade } & 0.0335 & 0.0336 & 0.0923 & 0.0590 & 0.0393 & 0.0603 & 0.0603 \\
\hline & $(0.0605)$ & $(0.0605)$ & $(0.152)$ & $(0.406)$ & $(0.410)$ & $(0.144)$ & $(0.144)$ \\
\hline \multirow[t]{2}{*}{ QTOB } & $0.0377^{*}$ & $0.0360 *$ & 0.140 & 0.0704 & 0.0630 & 0.0313 & 0.0313 \\
\hline & $(0.0209)$ & $(0.0214)$ & $(0.0917)$ & $(0.140)$ & $(0.154)$ & $(0.0362)$ & $(0.0388)$ \\
\hline \multirow[t]{2}{*}{ ROA } & 0.00114 & 0.00103 & 0.00306 & 0.0156 & 0.0156 & 0.00394 & 0.00364 \\
\hline & $(0.001)$ & $(0.001)$ & $(0.003)$ & $(0.013)$ & $(0.015)$ & $(0.002)$ & $(0.002)$ \\
\hline \multirow[t]{2}{*}{ ENDIV } & 0.151 & 0.172 & -0.0783 & 1.397 & 1.678 & 0.259 & 0.310 \\
\hline & $(0.117)$ & $(0.115)$ & $(0.507)$ & (1.276) & $(1.280)$ & $(0.242)$ & $(0.237)$ \\
\hline \multirow[t]{2}{*}{ Caixa } & 0.253 & 0.276 & $2.058^{*}$ & 1.876 & 2.152 & 0.544 & 0.584 \\
\hline & $(0.205)$ & $(0.209)$ & $(1.075)$ & $(1.477)$ & $(1.547)$ & $(0.387)$ & $(0.393)$ \\
\hline \multirow[t]{2}{*}{$\operatorname{lnMV}$} & $0.0534 * * *$ & $0.0531 * * *$ & $0.215^{* *}$ & $0.584 * * *$ & $0.611 * * *$ & $0.115^{* * *}$ & $0.114 * * *$ \\
\hline & $(0.0179)$ & $(0.0175)$ & $(0.0927)$ & $(0.145)$ & $(0.149)$ & $(0.0224)$ & $(0.0218)$ \\
\hline \multirow[t]{2}{*}{ Constant } & $-1.215^{* * *}$ & $-1.203 * * *$ & $-4.645^{* *}$ & & & $-2.754 * * *$ & $-2.695 * * *$ \\
\hline & $(0.409)$ & $(0.401)$ & $(1.980)$ & & & $(0.707)$ & $(0.691)$ \\
\hline Observations & 951 & 951 & 951 & 454 & 454 & 454 & 454 \\
\hline R-squared & 0.027 & 0.026 & 0.032 & & & 0.056 & 0.055 \\
\hline $\begin{array}{l}\text { Number of } \\
\text { idfirma }\end{array}$ & 183 & 183 & 183 & 69 & 69 & 69 & 69 \\
\hline
\end{tabular}

Robust standard errors in parentheses

$$
* * * \mathrm{p}<0.01, * * \mathrm{p}<0.05, * \mathrm{p}<0.1
$$


Tabela 9 - Fusões e Aquisições Empresas sem Controlador Definido (ExternosEC)

\begin{tabular}{|c|c|c|c|c|c|c|c|}
\hline VARIÁVEIS & Modelo1 & Modelo2 & Modelo 3 & Modelo 4 & Modelo 5 & Modelo 6 & Modelo 7 \\
\hline \multirow{2}{*}{ ExternosEC } & 0.103 & 0.0913 & $0.492 *$ & 0.697 & 0.674 & 0.177 & 0.158 \\
\hline & $(0.0745)$ & $(0.0756)$ & $(0.258)$ & $(0.548)$ & $(0.600)$ & $(0.122)$ & $(0.125)$ \\
\hline \multirow[t]{2}{*}{ tamdir } & 0.005 & 0.005 & -0.002 & 0.036 & 0.0363 & 0.009 & 0.008 \\
\hline & $(0.0117)$ & $(0.0118)$ & $(0.0425)$ & $(0.0737)$ & $(0.0763)$ & $(0.0193)$ & $(0.0195)$ \\
\hline \multirow[t]{2}{*}{ Dualidade } & 0.0341 & 0.0339 & 0.0897 & 0.0602 & 0.0402 & 0.0654 & 0.0641 \\
\hline & $(0.0604)$ & $(0.0605)$ & $(0.153)$ & $(0.404)$ & $(0.409)$ & $(0.143)$ & $(0.143)$ \\
\hline \multirow{2}{*}{ QTOB } & $0.0382 *$ & $0.0364^{*}$ & 0.137 & 0.0797 & 0.0693 & 0.0345 & 0.0336 \\
\hline & $(0.0214)$ & $(0.0219)$ & $(0.0932)$ & $(0.138)$ & $(0.153)$ & $(0.0362)$ & $(0.0386)$ \\
\hline \multirow[t]{2}{*}{$\mathrm{ROA}$} & 0.001 & 0.001 & 0.003 & 0.016 & 0.016 & 0.004 & 0.004 \\
\hline & $(0.001)$ & $(0.001)$ & $(0.003)$ & $(0.014)$ & $(0.0153)$ & $(0.002)$ & $(0.002)$ \\
\hline \multirow[t]{2}{*}{ ENDIV } & 0.152 & 0.172 & -0.0816 & 1.481 & 1.739 & 0.283 & 0.328 \\
\hline & $(0.117)$ & $(0.114)$ & $(0.506)$ & (1.263) & (1.259) & $(0.233)$ & $(0.227)$ \\
\hline \multirow[t]{2}{*}{ Caixa } & 0.253 & 0.277 & $2.056^{*}$ & 1.805 & 2.098 & 0.527 & 0.571 \\
\hline & $(0.205)$ & $(0.208)$ & (1.077) & (1.420) & (1.492) & $(0.375)$ & $(0.382)$ \\
\hline \multirow[t]{2}{*}{$\operatorname{lnMV}$} & $0.0531 * * *$ & $0.0530 * * *$ & $0.216^{* *}$ & $0.581 * * *$ & $0.610 * * *$ & $0.113 * * *$ & $0.112 * * *$ \\
\hline & $(0.0179)$ & $(0.0176)$ & $(0.0947)$ & $(0.147)$ & $(0.151)$ & $(0.0218)$ & $(0.0214)$ \\
\hline \multirow[t]{2}{*}{ Constant } & $-1.181 * * *$ & $-1.185 * * *$ & $-4.794 * *$ & & & $-2.539 * * *$ & $-2.536 * * *$ \\
\hline & $(0.390)$ & $(0.386)$ & $(2.108)$ & & & $(0.531)$ & $(0.527)$ \\
\hline Observations & 951 & 951 & 951 & 454 & 454 & 454 & 454 \\
\hline R-squared & 0.027 & 0.026 & 0.032 & & & 0.055 & 0.054 \\
\hline $\begin{array}{l}\text { Number of } \\
\text { idfirma }\end{array}$ & 183 & 183 & 183 & 69 & 69 & 69 & 69 \\
\hline
\end{tabular}

Robust standard errors in parentheses

$$
* * * \mathrm{p}<0.01, * * \mathrm{p}<0.05, * \mathrm{p}<0.1
$$


Tabela 10 - Fusões e Aquisições Empresas sem Controlador Definido (ExternosNEC)

\begin{tabular}{|c|c|c|c|c|c|c|c|}
\hline VARIÁVEIS & Modelo1 & Modelo 2 & Modelo 3 & Modelo 4 & Modelo 5 & Modelo 6 & Modelo 7 \\
\hline \multirow[t]{2}{*}{ ExternosNEC } & -0.0877 & -0.0800 & $-0.480 *$ & -0.578 & -0.578 & -0.141 & -0.130 \\
\hline & $(0.073)$ & $(0.075)$ & $(0.266)$ & $(0.550)$ & $(0.610)$ & $(0.120)$ & $(0.124)$ \\
\hline \multirow[t]{2}{*}{ tamdir } & 0.004 & 0.004 & -0.004 & 0.037 & 0.036 & 0.009 & 0.008 \\
\hline & $(0.012)$ & $(0.012)$ & $(0.0436)$ & $(0.0748)$ & $(0.0774)$ & $(0.0196)$ & $(0.0198)$ \\
\hline \multirow[t]{2}{*}{ Dualidade } & 0.0366 & 0.0362 & 0.101 & 0.0677 & 0.0465 & 0.0704 & 0.0686 \\
\hline & $(0.060)$ & $(0.060)$ & $(0.152)$ & $(0.402)$ & $(0.408)$ & $(0.141)$ & $(0.141)$ \\
\hline \multirow[t]{2}{*}{ QTOB } & $0.0382 *$ & $0.0365^{*}$ & 0.141 & 0.0798 & 0.0710 & 0.0360 & 0.0351 \\
\hline & $(0.021)$ & $(0.021)$ & $(0.092)$ & $(0.142)$ & $(0.156)$ & $(0.037)$ & $(0.039)$ \\
\hline \multirow[t]{2}{*}{ ROA } & 0.001 & 0.001 & 0.003 & 0.017 & 0.020 & 0.004 & 0.004 \\
\hline & $(0.001)$ & $(0.001)$ & $(0.003)$ & $(0.015)$ & $(0.016)$ & $(0.002)$ & $(0.003)$ \\
\hline \multirow[t]{2}{*}{ ENDIV } & 0.152 & 0.173 & -0.0757 & 1.528 & 1.791 & 0.294 & 0.339 \\
\hline & $(0.117)$ & $(0.115)$ & $(0.506)$ & (1.298) & (1.298) & $(0.239)$ & $(0.233)$ \\
\hline \multirow[t]{2}{*}{ Caixa } & 0.253 & 0.277 & $2.059^{*}$ & 1.773 & 2.061 & 0.515 & 0.560 \\
\hline & $(0.203)$ & $(0.207)$ & (1.064) & $(1.425)$ & (1.502) & $(0.374)$ & $(0.382)$ \\
\hline \multirow[t]{2}{*}{$\operatorname{lnMV}$} & $0.0523 * * *$ & $0.0523 * * *$ & $0.212 * *$ & $0.577 * * *$ & $0.606^{* * *}$ & $0.110^{* * *}$ & $0.110 * * *$ \\
\hline & $(0.0176)$ & $(0.0174)$ & $(0.0922)$ & $(0.149)$ & $(0.153)$ & $(0.0218)$ & $(0.0213)$ \\
\hline \multirow[t]{2}{*}{ Constant } & $-1.078 * * *$ & $-1.093 * * *$ & $-4.282 * *$ & & & $-2.333 * * *$ & $-2.353 * * *$ \\
\hline & $(0.393)$ & $(0.387)$ & $(2.038)$ & & & $(0.538)$ & $(0.526)$ \\
\hline Observations & 951 & 951 & 951 & 454 & 454 & 454 & 454 \\
\hline R-squared & 0.026 & 0.026 & 0.031 & & & 0.053 & 0.053 \\
\hline $\begin{array}{l}\text { Number of } \\
\text { idfirma }\end{array}$ & 183 & 183 & 183 & 69 & 69 & 69 & 69 \\
\hline
\end{tabular}

Robust standard errors in parentheses

$$
* * * \mathrm{p}<0.01, * * \mathrm{p}<0.05, * \mathrm{p}<0.1
$$


As tabelas 8, 9 e 10 apresentam os resultados obtidos através da regressão especificamente aplicada a empresas que não contem com a figura do controlador detentor de mais de $50 \%$ das ações com direito a voto. Como poderia ser esperado, as variáveis que na amostra inicial mostravam-se relevantes em alguns modelos, perdem significância.

Os resultados associados às empresas com controlador majoritário foram expostos nas tabelas 11, 12 e 13. A partir da análise dos coeficientes expostos na tabela, podemos observar que as variáveis relacionadas a independência do conselho de administração apresentaram-se positivamente relacionadas a maior agressividade na busca de transações de fusões e aquisições para todas as métricas utilizadas quando utilizadas como variáveis de independência simultaneamente ExternosEC e ExternosNEC ou quando utilizada especificamente ExternosNEC.

Nos 5 modelos apresentados pelo menos a variável relacionada à presença de externos não eleitos pelo controlador no conselho mostra-se associada a uma maior agressividade da empresa em sua política de fusões e aquisições.

Diante desse cenário, a hipótese de um conselho inerte se desconstrói, restam então duas alternativas opostas. Primeiramente, o conselheiro externo por ser, em geral, um executivo de expressão e com expressiva rede de contatos, pode viabilizar negócios e reduzir barreiras inserindo empresas de estrutura essencialmente familiar no centro dos fluxos de negócios corporativos gerando, assim, valor aos acionistas. 
Tabela 11 - Fusões e Aquisições Empresas com Controlador Definido (ExternosEC e ExternosNEC)

\begin{tabular}{|c|c|c|c|c|c|c|c|}
\hline VARIÁVEIS & Modelo 1 & Modelo 2 & Modelo 3 & Modelo 4 & Modelo 5 & Modelo 6 & Modelo 7 \\
\hline \multirow[t]{2}{*}{ ExternosEC } & $0.139 * *$ & $0.139 * *$ & $0.775 * * *$ & $1.955^{* * *}$ & $2.167 * * *$ & $0.479 * * *$ & $0.482 * * *$ \\
\hline & $(0.0601)$ & $(0.0583)$ & $(0.295)$ & $(0.633)$ & $(0.656)$ & $(0.181)$ & $(0.174)$ \\
\hline \multirow[t]{2}{*}{ ExternosNEC } & $0.284 * * *$ & $0.291 * * *$ & $0.874 * *$ & $2.704 * * *$ & $2.993 * * *$ & $0.743 * * *$ & $0.762 * * *$ \\
\hline & $(0.0980)$ & $(0.0941)$ & $(0.396)$ & $(0.743)$ & $(0.738)$ & $(0.218)$ & $(0.205)$ \\
\hline \multirow[t]{2}{*}{ tamdir } & $-0.0171^{*}$ & $-0.0168^{*}$ & -0.0409 & $-0.142 *$ & $-0.151 * *$ & $-0.0365^{*}$ & $-0.0361 *$ \\
\hline & $(0.009)$ & $(0.009)$ & $(0.0446)$ & $(0.073)$ & $(0.077)$ & $(0.019)$ & $(0.020)$ \\
\hline \multirow[t]{2}{*}{ Dualidade } & 0.0134 & 0.00410 & 0.0968 & 0.0981 & 0.0324 & 0.0154 & -0.00815 \\
\hline & $(0.0378)$ & $(0.0356)$ & $(0.231)$ & $(0.307)$ & $(0.304)$ & $(0.0931)$ & $(0.0899)$ \\
\hline \multirow[t]{2}{*}{ QTOB } & $0.0233 *$ & $0.0210^{*}$ & $0.135^{* * *}$ & -0.0637 & -0.0853 & 0.00987 & 0.00489 \\
\hline & $(0.013)$ & $(0.0127)$ & $(0.0516)$ & $(0.114)$ & $(0.114)$ & $(0.0280)$ & $(0.0263)$ \\
\hline \multirow[t]{2}{*}{ ROA } & 0.001 & 0.000 & 0.003 & 0.010 & 0.007 & 0.004 & 0.003 \\
\hline & $(0.001)$ & $(0.001)$ & $(0.002)$ & $(0.0128)$ & $(0.0125)$ & $(0.004)$ & $(0.004)$ \\
\hline \multirow[t]{2}{*}{ ENDIV } & -0.0633 & -0.0799 & -0.0995 & -0.487 & -0.686 & -0.0804 & -0.124 \\
\hline & $(0.130)$ & $(0.127)$ & $(0.429)$ & $(0.992)$ & $(0.987)$ & $(0.309)$ & $(0.303)$ \\
\hline \multirow[t]{2}{*}{ Caixa } & -0.0970 & -0.0988 & -0.635 & -0.734 & -0.739 & -0.213 & -0.217 \\
\hline & $(0.0836)$ & $(0.0821)$ & $(0.416)$ & $(0.586)$ & $(0.570)$ & $(0.233)$ & $(0.226)$ \\
\hline \multirow[t]{2}{*}{$\operatorname{lnMV}$} & $0.0342 *$ & $0.0347 *$ & $0.160 * *$ & $0.402 * *$ & $0.444 * * *$ & $0.0941 *$ & $0.0974 * *$ \\
\hline & $(0.0189)$ & $(0.0186)$ & $(0.0685)$ & $(0.157)$ & $(0.153)$ & $(0.0480)$ & $(0.0465)$ \\
\hline \multirow[t]{2}{*}{ Constant } & -0.644 & $-0.653 *$ & $-3.452 * *$ & & & $-1.963^{*}$ & $-2.033^{* *}$ \\
\hline & $(0.394)$ & $(0.387)$ & $(1.413)$ & & & $(1.027)$ & $(0.993)$ \\
\hline Observations & 1,584 & 1,584 & 1,584 & 635 & 629 & 635 & 635 \\
\hline R-squared & 0.023 & 0.024 & 0.017 & & & 0.057 & 0.057 \\
\hline $\begin{array}{l}\text { Number of } \\
\text { idfirma }\end{array}$ & 280 & 280 & 280 & 101 & 100 & 101 & 101 \\
\hline
\end{tabular}

Robust standard errors in parentheses

$$
* * * \mathrm{p}<0.01, * * \mathrm{p}<0.05, * \mathrm{p}<0.1
$$


Tabela 12 - Fusões e Aquisições com Empresas com Controlador Definido (ExternosEC)

\begin{tabular}{|c|c|c|c|c|c|c|c|}
\hline Variáveis & Modelo1 & Modelo 2 & Modelo 3 & Modelo 4 & Modelo 5 & Modelo 6 & Modelo 7 \\
\hline \multirow[t]{2}{*}{ ExternosEC } & -0.0592 & -0.0634 & 0.166 & -0.314 & -0.342 & -0.159 & -0.136 \\
\hline & $(0.071)$ & $(0.070)$ & $(0.296)$ & $(0.385)$ & $(0.397)$ & $(0.138)$ & $(0.141)$ \\
\hline \multirow[t]{2}{*}{ tamdir } & -0.0152 & -0.0149 & -0.0351 & -0.108 & -0.109 & -0.0318 & -0.0319 \\
\hline & $(0.010)$ & $(0.009)$ & $(0.045)$ & $(0.0696)$ & $(0.0724)$ & $(0.0213)$ & $(0.021)$ \\
\hline \multirow[t]{2}{*}{ Dualidade } & 0.0191 & 0.00996 & 0.114 & 0.195 & 0.128 & 0.0480 & 0.0226 \\
\hline & $(0.0388)$ & $(0.0362)$ & $(0.233)$ & $(0.305)$ & $(0.293)$ & $(0.0958)$ & $(0.0903)$ \\
\hline \multirow[t]{2}{*}{ QTOB } & $0.0236^{*}$ & 0.0213 & $0.136^{* *}$ & -0.0217 & -0.0408 & 0.012 & 0.010 \\
\hline & $(0.0139)$ & $(0.0136)$ & $(0.0530)$ & $(0.114)$ & $(0.114)$ & $(0.0286)$ & $(0.0281)$ \\
\hline \multirow[t]{2}{*}{ ROA } & 0.001 & 0.001 & 0.003 & 0.011 & 0.008 & 0.004 & 0.003 \\
\hline & $(0.001)$ & $(0.001)$ & $(0.002)$ & $(0.013)$ & $(0.012)$ & $(0.00402)$ & $(0.004)$ \\
\hline \multirow[t]{2}{*}{ ENDIV } & -0.0503 & -0.0666 & -0.0595 & -0.519 & -0.763 & -0.0744 & -0.169 \\
\hline & $(0.130)$ & $(0.127)$ & $(0.427)$ & $(0.976)$ & $(0.965)$ & $(0.314)$ & $(0.307)$ \\
\hline \multirow[t]{2}{*}{ Caixa } & -0.111 & -0.113 & -0.677 & -0.721 & -0.714 & -0.252 & -0.218 \\
\hline & $(0.0846)$ & $(0.0829)$ & $(0.415)$ & $(0.602)$ & $(0.592)$ & $(0.244)$ & $(0.244)$ \\
\hline \multirow[t]{2}{*}{$\operatorname{lnMV}$} & $0.038 * *$ & $0.0382 * *$ & $0.171 * *$ & $0.414 * * *$ & $0.459 * * *$ & $0.113 * *$ & $0.117 * *$ \\
\hline & $(0.0191)$ & $(0.019)$ & $(0.067)$ & $(0.157)$ & $(0.153)$ & $(0.051)$ & $(0.049)$ \\
\hline \multirow[t]{2}{*}{ Constant } & -0.540 & -0.547 & $-3.132 * *$ & & & $-1.817^{*}$ & $-1.889 *$ \\
\hline & $(0.395)$ & $(0.389)$ & $(1.450)$ & & & (1.093) & $(1.054)$ \\
\hline Observations & 1,584 & 1,584 & 1,584 & 635 & 629 & 629 & 629 \\
\hline R-squared & 0.017 & 0.017 & 0.014 & & & 0.045 & 0.045 \\
\hline $\begin{array}{l}\text { Number of } \\
\text { idfirma }\end{array}$ & 280 & 280 & 280 & 101 & 100 & 100 & 100 \\
\hline
\end{tabular}

Robust standard errors in parentheses

$$
* * * \mathrm{p}<0.01, * * \mathrm{p}<0.05, * \mathrm{p}<0.1
$$


Tabela 13 - Fusões e Aquisições com Empresas com Controlador Definido (ExternosNEC)

\section{VARIÁVEIS Modelo1 $\quad$ Modelo 2 Modelo 3 Modelo 4 Modelo 5 Modelo 6 Modelo 7}

\begin{tabular}{|c|c|c|c|c|c|c|c|}
\hline \multirow[t]{2}{*}{ ExternosNEC } & $0.159^{*}$ & $0.165^{*}$ & 0.175 & $0.844 * *$ & $0.930 * *$ & $0.352 * *$ & $0.322 * *$ \\
\hline & $(0.087)$ & $(0.084)$ & $(0.347)$ & $(0.406)$ & $(0.406)$ & $(0.135)$ & $(0.140)$ \\
\hline \multirow[t]{2}{*}{ tamdir } & $-0.0168^{*}$ & $-0.0165^{*}$ & -0.0393 & $-0.126^{*}$ & $-0.130 *$ & $-0.0363 *$ & $-0.0361^{*}$ \\
\hline & $(0.009)$ & $(0.009)$ & $(0.045)$ & $(0.068)$ & $(0.071)$ & $(0.020)$ & $(0.020)$ \\
\hline \multirow[t]{2}{*}{ Dualidade } & 0.0165 & 0.00722 & 0.114 & 0.164 & 0.0989 & 0.0367 & 0.0126 \\
\hline & $(0.0381)$ & $(0.0356)$ & $(0.232)$ & $(0.304)$ & $(0.296)$ & $(0.0920)$ & $(0.0880)$ \\
\hline \multirow[t]{2}{*}{ QTOB } & $0.0218 *$ & 0.0195 & $0.127 * *$ & -0.0644 & -0.0869 & -0.000699 & -0.00247 \\
\hline & $(0.013)$ & $(0.013)$ & $(0.051)$ & $(0.112)$ & $(0.111)$ & $(0.028)$ & $(0.028)$ \\
\hline \multirow[t]{2}{*}{ ROA } & 0.001 & 0.001 & 0.003 & 0.011 & 0.008 & 0.003 & 0.003 \\
\hline & $(0.001)$ & $(0.001)$ & $(0.002)$ & $(0.0125)$ & $(0.0123)$ & $(0.00398)$ & $(0.00387)$ \\
\hline \multirow[t]{2}{*}{ ENDIV } & -0.0581 & -0.0746 & -0.0704 & -0.457 & -0.669 & -0.0608 & -0.156 \\
\hline & $(0.129)$ & $(0.127)$ & $(0.428)$ & $(0.981)$ & $(0.971)$ & $(0.312)$ & $(0.305)$ \\
\hline \multirow[t]{2}{*}{ Caixa } & -0.108 & -0.110 & $-0.695 *$ & -0.872 & -0.888 & -0.275 & -0.241 \\
\hline & $(0.0846)$ & $(0.0831)$ & $(0.420)$ & $(0.586)$ & $(0.569)$ & $(0.238)$ & $(0.239)$ \\
\hline \multirow[t]{2}{*}{$\operatorname{lnMV}$} & $0.0347^{*}$ & $0.0352 *$ & $0.163 * *$ & $0.409 * * *$ & $0.451 * * *$ & $0.110 * *$ & $0.113 * *$ \\
\hline & $(0.0191)$ & $(0.0187)$ & $(0.0691)$ & $(0.156)$ & $(0.152)$ & $(0.0507)$ & $(0.0487)$ \\
\hline \multirow[t]{2}{*}{ Constant } & -0.537 & -0.546 & $-2.854 * *$ & & & $-1.875^{*}$ & $-1.933 *$ \\
\hline & $(0.396)$ & $(0.387)$ & $(1.404)$ & & & (1.087) & $(1.050)$ \\
\hline Observations & 1,584 & 1,584 & 1,584 & 635 & 629 & 629 & 629 \\
\hline R-squared & 0.021 & 0.022 & 0.014 & & & 0.054 & 0.053 \\
\hline $\begin{array}{l}\text { Number of } \\
\text { idfirma }\end{array}$ & 280 & 280 & 280 & 101 & 100 & 100 & 100 \\
\hline
\end{tabular}

Robust standard errors in parentheses

$$
* * * \mathrm{p}<0.01, * * \mathrm{p}<0.05, * \mathrm{p}<0.1
$$


Em contrapartida, os conselheiros externos poderiam estar destruindo valor levando a acordos desvantajosos, seja por uma visão equivocada, seja por algum incentivo pessoal como a possibilidade de lançar os holofotes sobre a empresa da qual ele faz parte do conselho e, consequentemente, colocar-se em posição de destaque.

Para verificar qual dessas hipóteses se mostra vigente, a subseção seguinte confrontará os modelos contra os múltiplos de valor da empresa.

\subsection{Modelos de Performance}

Para considerarmos os múltiplos como proxy do desempenho da empresa, vamos tomar a relação do lucro e do valor patrimonial da companhia contra seu valor de mercado. Os modelos serão, essencialmente, semelhantes aos modelos de base e aos experimentados na seção anterior.

Como variáveis dependentes foram consideradas a divisão do patrimônio líquido pelo valor de mercado (modelos 1, 3 e 5) e a divisão do lucro líquido pelo valor de mercado (modelos 2, 4 e 6). Esses dois indicadores são oriundos, respectivamente, do índice preço-livro (price-to-book ratio) e do índice preço/lucro (price-to-earnings ratio), indicadores largamente utilizados na literatura.

A troca entre numeradores e denominadores impede a excessiva oscilação em casos nos quais o denominador seja muito próximo a zero. Invertendo as relações, esse problema se dilui uma vez que não há valor de mercado igual a zero ou proporcionalmente tão próximo como acontece com os indicadores de lucro e patrimônio que podem oscilar livremente entre valores positivos e negativos. 
Tabela 14 - Performance (ExternosEC e ExternosNEC)

\begin{tabular}{|c|c|c|c|c|c|c|}
\hline VARIÁVEIS & Modelo 1 & Modelo 2 & Modelo 3 & Modelo 4 & Modelo 5 & Modelo 6 \\
\hline \multirow[t]{2}{*}{ ExternosEC } & -0.259 & -0.163 & 0.104 & 0.0496 & -0.259 & $-0.354 * *$ \\
\hline & $(0.448)$ & $(0.112)$ & $(0.665)$ & $(0.185)$ & $(0.636)$ & $(0.148)$ \\
\hline \multirow[t]{2}{*}{ ExternosNEC } & -0.360 & -0.160 & -0.105 & 0.0129 & -0.256 & $-0.345 * *$ \\
\hline & $(0.433)$ & $(0.114)$ & $(0.639)$ & $(0.179)$ & $(0.561)$ & $(0.162)$ \\
\hline \multirow[t]{2}{*}{ tamdir } & -0.020 & -0.001 & -0.010 & -0.002 & -0.046 & 0.000 \\
\hline & $(0.025)$ & $(0.009)$ & $(0.039)$ & $(0.012)$ & $(0.031)$ & $(0.011)$ \\
\hline \multirow[t]{2}{*}{ Dualidade } & $-0.202 * *$ & $-0.0623 * *$ & $-0.413 * * *$ & -0.0455 & -0.0442 & $-0.086^{*}$ \\
\hline & $(0.094)$ & $(0.0304)$ & $(0.146)$ & $(0.0351)$ & $(0.107)$ & $(0.052)$ \\
\hline \multirow[t]{2}{*}{ QTOB } & & -0.0167 & & -0.00999 & & -0.0107 \\
\hline & & $(0.0318)$ & & $(0.0606)$ & & $(0.035)$ \\
\hline \multirow[t]{2}{*}{ ROA } & $0.0113 * * *$ & $0.0159 * * *$ & $0.00825 *$ & $0.0189 * * *$ & $0.0134 * * *$ & $0.013 * * *$ \\
\hline & $(0.003)$ & $(0.002)$ & $(0.004)$ & $(0.003)$ & $(0.003)$ & $(0.002)$ \\
\hline \multirow[t]{2}{*}{ ENDIV } & $-0.806^{*}$ & -0.161 & $-1.741 * *$ & 0.0145 & 0.395 & $-0.276 * *$ \\
\hline & $(0.416)$ & $(0.136)$ & $(0.749)$ & $(0.200)$ & $(0.426)$ & $(0.138)$ \\
\hline \multirow[t]{2}{*}{ Caixa } & 0.478 & -0.121 & 0.569 & -0.161 & 0.657 & -0.030 \\
\hline & $(0.360)$ & $(0.103)$ & $(0.514)$ & $(0.218)$ & $(0.505)$ & $(0.103)$ \\
\hline \multirow[t]{2}{*}{$\operatorname{lnMV}$} & $-0.375 * * *$ & $0.151 * * *$ & $-0.378 * *$ & $0.151 * * *$ & $-0.496 * * *$ & $0.133 * * *$ \\
\hline & $(0.102)$ & $(0.025)$ & $(0.179)$ & $(0.042)$ & $(0.123)$ & $(0.029)$ \\
\hline \multirow[t]{2}{*}{ Constant } & $9.326 * * *$ & $-3.016^{* * *}$ & $9.346^{* *}$ & $-3.261 * * *$ & $11.57 * * *$ & $-2.457 * * *$ \\
\hline & $(2.095)$ & $(0.514)$ & (3.669) & $(0.885)$ & $(2.538)$ & $(0.606)$ \\
\hline Observations & 1,617 & 1,618 & 729 & 727 & 888 & 891 \\
\hline R-squared & 0.099 & 0.483 & 0.123 & 0.508 & 0.156 & 0.452 \\
\hline $\begin{array}{l}\text { Number of } \\
\text { idfirma }\end{array}$ & 274 & 275 & 144 & 144 & 192 & 193 \\
\hline
\end{tabular}

Robust standard errors in parentheses

$$
* * * \mathrm{p}<0.01, * * \mathrm{p}<0.05,{ }^{*} \mathrm{p}<0.1
$$


Tabela 15 - Performance (ExternosEC)

\begin{tabular}{|c|c|c|c|c|c|c|}
\hline VARIÁVEIS & Modelo1 & Modelo 2 & Modelo 3 & Modelo 4 & Modelo 5 & Modelo 6 \\
\hline \multirow[t]{2}{*}{ ExternosEC } & -0.031 & -0.101 & 0.038 & 0.080 & -0.091 & -0.235 \\
\hline & $(0.047)$ & $(0.156)$ & $(0.073)$ & $(0.210)$ & $(0.064)$ & $(0.226)$ \\
\hline \multirow[t]{2}{*}{ tamdir } & -0.001 & -0.003 & -0.002 & 0.0159 & -0.00219 & -0.0336 \\
\hline & $(0.009)$ & $(0.024)$ & $(0.012)$ & $(0.038)$ & $(0.010)$ & $(0.028)$ \\
\hline \multirow[t]{2}{*}{ Dualidade } & $-0.068 * *$ & $-0.156^{*}$ & -0.045 & $-0.321 * *$ & $-0.100 *$ & -0.020 \\
\hline & $(0.030)$ & $(0.087)$ & $(0.035)$ & $(0.146)$ & $(0.051)$ & $(0.102)$ \\
\hline \multirow[t]{2}{*}{ QTOB } & -0.0179 & $-0.511 * * *$ & -0.00979 & $-0.435 * * *$ & -0.0131 & $-0.513 * * *$ \\
\hline & $(0.032)$ & $(0.097)$ & $(0.060)$ & $(0.137)$ & $(0.036)$ & $(0.138)$ \\
\hline \multirow[t]{2}{*}{ ROA } & $0.016^{* * *}$ & $0.008 * * *$ & $0.019 * * *$ & $0.007 *$ & $0.013 * * *$ & $0.009 * * *$ \\
\hline & $(0.002)$ & $(0.003)$ & $(0.003)$ & $(0.004)$ & $(0.002)$ & $(0.003)$ \\
\hline \multirow[t]{2}{*}{ ENDIV } & -0.168 & $-0.938 * *$ & 0.0148 & $-1.676 * * *$ & $-0.308 * *$ & 0.0360 \\
\hline & $(0.135)$ & $(0.367)$ & (0.199) & $(0.609)$ & $(0.136)$ & $(0.467)$ \\
\hline \multirow[t]{2}{*}{ Caixa } & -0.114 & 0.499 & -0.161 & 0.115 & -0.00601 & $0.852^{*}$ \\
\hline & $(0.103)$ & $(0.341)$ & $(0.218)$ & $(0.499)$ & $(0.100)$ & $(0.450)$ \\
\hline \multirow[t]{2}{*}{$\ln M V$} & $0.151 * * *$ & $-0.292 * * *$ & $0.151 * * *$ & $-0.324 * *$ & $0.130 * * *$ & $-0.388 * * *$ \\
\hline & $(0.025)$ & $(0.088)$ & $(0.042)$ & $(0.156)$ & $(0.030)$ & $(0.117)$ \\
\hline \multirow[t]{2}{*}{ Constant } & $-3.143 * * *$ & $8.091 * * *$ & $-3.248 * * *$ & $8.719 * * *$ & $-2.623 * * *$ & $10.01 * * *$ \\
\hline & $(0.511)$ & $(1.749)$ & $(0.868)$ & $(3.176)$ & $(0.599)$ & $(2.258)$ \\
\hline Observations & 1,618 & 1,617 & 727 & 729 & 891 & 888 \\
\hline R-squared & 0.482 & 0.206 & 0.508 & 0.203 & 0.444 & 0.266 \\
\hline $\begin{array}{l}\text { Number of } \\
\text { idfirma }\end{array}$ & 275 & 274 & 144 & 144 & 193 & 192 \\
\hline
\end{tabular}

Robust standard errors in parentheses

$$
* * * \mathrm{p}<0.01, * * \mathrm{p}<0.05, * \mathrm{p}<0.1
$$


Tabela 16 - Performance (ExternosNEC)

\begin{tabular}{|c|c|c|c|c|c|c|}
\hline VARIÁVEIS & Modelo1 & Modelo 2 & Modelo 3 & Modelo 4 & Modelo 5 & Modelo 6 \\
\hline \multirow[t]{2}{*}{ ExternosNEC } & -0.00980 & 0.0451 & -0.0330 & -0.0431 & -0.0202 & 0.178 \\
\hline & $(0.0469)$ & $(0.152)$ & $(0.0690)$ & $(0.210)$ & $(0.0618)$ & $(0.170)$ \\
\hline \multirow[t]{2}{*}{ tamdir } & -0.000712 & -0.00316 & -0.00200 & 0.0159 & -0.000733 & -0.0337 \\
\hline & $(0.00854)$ & $(0.0240)$ & $(0.0123)$ & $(0.0379)$ & $(0.00993)$ & $(0.0272)$ \\
\hline \multirow[t]{2}{*}{ Dualidade } & $-0.0689 * *$ & $-0.159 *$ & -0.0437 & $-0.318 * *$ & $-0.0999 *$ & -0.0281 \\
\hline & $(0.0304)$ & $(0.0877)$ & $(0.0353)$ & $(0.146)$ & $(0.0527)$ & $(0.104)$ \\
\hline \multirow[t]{2}{*}{ QTOB } & -0.0164 & $-0.509 * * *$ & -0.00966 & $-0.436 * * *$ & -0.00890 & $-0.511 * * *$ \\
\hline & $(0.0319)$ & $(0.0975)$ & $(0.0601)$ & $(0.138)$ & $(0.0365)$ & $(0.138)$ \\
\hline \multirow[t]{2}{*}{ ROA } & $0.0158 * * *$ & $0.00786 * * *$ & $0.0189 * * *$ & $0.00689 *$ & $0.0128 * * *$ & $0.00846^{* * *}$ \\
\hline & $(0.00179)$ & $(0.00283)$ & $(0.00282)$ & $(0.00371)$ & $(0.00207)$ & $(0.00298)$ \\
\hline \multirow[t]{2}{*}{ ENDIV } & -0.167 & $-0.939 * *$ & 0.0156 & $-1.674 * * *$ & $-0.305 * *$ & 0.0218 \\
\hline & $(0.136)$ & $(0.368)$ & $(0.200)$ & $(0.611)$ & $(0.137)$ & $(0.469)$ \\
\hline \multirow[t]{2}{*}{ Caixa } & -0.107 & 0.514 & -0.164 & 0.106 & 0.0128 & $0.884^{*}$ \\
\hline & $(0.102)$ & $(0.343)$ & $(0.215)$ & $(0.507)$ & $(0.0989)$ & $(0.458)$ \\
\hline \multirow[t]{2}{*}{$\ln \mathrm{MV}$} & $0.152 * * *$ & $-0.291 * * *$ & $0.150 * * *$ & $-0.324 * *$ & $0.132 * * *$ & $-0.388 * * *$ \\
\hline & $(0.0253)$ & $(0.0888)$ & $(0.0420)$ & $(0.157)$ & $(0.0301)$ & $(0.117)$ \\
\hline \multirow[t]{2}{*}{ Constant } & $-3.174 * * *$ & $7.992 * * *$ & $-3.208 * * *$ & $8.791 * * *$ & $-2.739 * * *$ & $9.809 * * *$ \\
\hline & $(0.512)$ & (1.783) & $(0.861)$ & $(3.234)$ & $(0.604)$ & (2.291) \\
\hline Observations & 1,618 & 1,617 & 727 & 729 & 891 & 888 \\
\hline R-squared & 0.482 & 0.205 & 0.508 & 0.203 & 0.443 & 0.264 \\
\hline $\begin{array}{l}\text { Number of } \\
\text { idfirma }\end{array}$ & 275 & 274 & 144 & 144 & 193 & 192 \\
\hline
\end{tabular}

Robust standard errors in parentheses

$$
* * * \mathrm{p}<0.01, * * \mathrm{p}<0.05, * \mathrm{p}<0.1
$$


De modo semelhante ao verificado na seção anterior, nas tabelas 14,15 e 16 os modelos 1 e 2 são referentes ao uso da amostra completa de demonstrativos. Os modelos 3 e 4 limitam-se às empresas sem acionista majoritário definido, enquanto os modelos 5 e 6 pelo contrário consideraram apenas as empresas com controlador definido no período de referência.

A tabela 14 apresenta significância aos níveis usuais apenas no modelo 6 . Observa-se, todavia, que esse indicador não se mostra robusto à segmentação entre externos eleitos pelo controlador ou por minoritários conforme resultados expostos nas tabelas 15 e 16 .

\subsection{Modelos de Giro nas Carteiras dos Fundos de Investimento}

$\mathrm{Na}$ busca por verificar os pontos de impacto das principais práticas associadas a governança corporativa na empresa, desenha-se sobretudo a característica de um selo. De alguma maneira valer-se de algumas dessas condições poderia ajudar a empresa a ser mais bem vista pelo mercado e outros frutos seriam consequência - como a capilaridade no mercado de fusões e aquisições e maior confiança dos investidores na persistência dos resultados.

Para esse selo persistir e se condicionar válido, é importante que a confiança do investidor seja retroalimentada, ou seja, o investidor que compre o papel, tendo a escolha, permaneça com ele pois suas premissas demonstraram-se válidas ao longo do tempo - o

papel mostrou retorno e desempenho consistente com o esperado, sem surpresas para mais ou para menos. 
Uma maneira de verificar esse ponto seria acompanhar quanto tempo um papel fica na carteira de um investidor que não tem nenhuma imposição externa a mudar sua alocação. Verificar esse ponto no mercado amplo apresenta fortes restrições, pois ao considerar compras e vendas negociadas no mercado aberto, reposicionamentos vindos de regulações globais, movimentos de investidores estrangeiros ou a simples mudança de ânimos irracional do mercado de investidores individuais, poderia levar um resíduo inapropriado para a amostra.

Para fazer essa verificação de maneira mais cirúrgica, o ideal seria observar carteiras em que se pudesse analisar em volume as compras, vendas e posições efetivas desse canal investidor. Investidores internacionais e locais na pessoa física, não oferecem, naturalmente, suas carteiras a público, os investidores institucionais, figuram, portanto, como o caminho de acesso mais promissor para a verificação, dentre eles, os fundos de investimento mútuos ativos mostram particular interesse por suas decisões estarem essencialmente livres às premissas do gestor.

No Brasil os fundos, regulados pela ICVM 555, lançam mensalmente suas posições e as movimentações operadas no mês no mercado de ações. Essa característica coloca o mercado brasileiro como um ambiente especialmente propício a esse experimento somado à já citada particular distribuição de estrutura societária.

Quando um gestor de fundos ativos compra um papel ele pode formar essa posição por convicções de longo prazo ou por especulação. Neste segundo caso, é esperado que o gestor compre e venda dentro de um curto período sua posição, de modo que o giro de sua carteira será elevado, pois acredita que há uma assimetria de mercado da qual pretende se aproveitar, mas assim que o ajuste ocorrer, sairá da posição. No primeiro caso, todavia, 
o gestor se posiciona por acreditar em uma tese de investimento a ser realizada, de maneira que os únicos incentivos a sair dessa posição estão em a empresa ter uma performance muito distinta da esperada ou o modelo de análise não se mostrar robusto devido a mudanças na característica das empresas.

Fica claro, portanto, que o elevado volume negociado em relação às posições dos fundos nos ativos, figura como um indicador inverso à confiabilidade desses ativos para o mercado. Desse modo quanto menor o giro dos fundos encontrado, melhor o índice de confiabilidade no ativo - indicador que gostaríamos de verificar para testar a robustez da tentativa de uso da governança corporativa como um selo para o mercado.

Para realizar essa investigação, criamos um indicador composto pela soma de todas as compras e vendas realizadas pela indústria de fundos no período, dividida pela soma das posições finais dos fundos nos papéis da empresa ao fim de cada ano. Após montar e calcular esse indicador para todos os pares empresa-ano, foi possível aplicar essa variável a um modelo semelhante ao já explorado nas seções anteriores.

Neste caso, contudo, observamos uma particular relevância da liquidez desses ativos na bolsa de valores. Como tratamos de posições que precisam ser negociadas em mercado aberto, empresas com mais ou menos volume negociado no período podem ter comportamentos significativamente diferentes.

Dessa maneira, segmentamos as análises primeiramente em modelos 1,2 e 3 que representam, respectivamente, a amostra ampla de empresas, as empresas com volume total negociado no ano abaixo de R\$ 1 bilhão e, por fim, as empresas com volume total negociado em bolsa no período acima desse valor. 
As tabelas foram segmentadas de modo que a tabela 17 traz os dados de todas as empresas, a tabela 18 reflete apenas os dados das empresas sem um controlador definido e a tabela 19 apresenta os dados das empresas com um acionista detentor de pelo menos $50 \%$ das ações ordinárias da companhia todas elas utilizando ambas as variáveis relativas a externalidade do conselho.

Em linha com as verificações presentes nos itens anteriores as tabelas 20, 21 e 22 refletem as distinções antevistas nas tabelas 17, 18 e 19, mas utiliza apenas a variável de externos eleitos pelo controlador nos modelos. As tabelas 23, 24 e 25, em contrapartida, utilizam apenas a variável de externos não eleitos pelo controlador.

A partir de uma leitura simples das tabelas 17 e 18 é possível extrair que nenhuma das variáveis de interesse apresenta coeficiente significantes aos níveis usuais. Esse resultado segue em linha com a proposta central deste estudo uma vez que a tabela 19 , que apresenta os resultados de empresas com controlador, apresenta coeficientes significantes.

Seus resultados apontam para uma relação negativa e significativamente diferente de zero em termos estatísticos entre o percentual de membros externos e não eleitos pelo controlador e o giro dos fundos de investimento dos papéis da empresa em suas carteiras. Esse resultado aparece no modelo 1 a 10\% de significância no modelo 1, mas aumenta sua confiança no modelo 2 , uma vez que a variabilidade do estimador manteve-se próxima à global, mas sua média aumentou substancialmente. As empresas com volume negociado no ano acima de R\$ 1 bilhão não mostraram indicadores significantes a níveis

Os resultados encontrados nos modelos 1 e 2 da tabela 19 estão em linha com os verificados nas seções anteriores e reafirmam a hipótese de uso da governança como um 
selo para o mercado, uma vez que se forma uma evidencia de que o mercado olha esses indicadores e se comporta de maneira responsiva a eles.

Tabela 17 - Giro dos Fundos - Todas as Empresas (ExternosEC e ExternosNEC)

\begin{tabular}{|c|c|c|c|}
\hline VARIÁVEIS & Modelo 1 & Modelo 2 & Modelo 3 \\
\hline \multirow[t]{2}{*}{ ExternosEC } & 0.533 & -0.806 & -1.033 \\
\hline & $(1.605)$ & $(1.684)$ & $(3.484)$ \\
\hline \multirow[t]{2}{*}{ ExternosNEC } & -0.356 & -0.580 & -2.829 \\
\hline & $(1.617)$ & $(1.653)$ & $(3.612)$ \\
\hline \multirow[t]{2}{*}{ tamdir } & 0.0154 & -0.0661 & 0.154 \\
\hline & $(0.108)$ & $(0.124)$ & $(0.191)$ \\
\hline \multirow[t]{2}{*}{ Dualidade } & -0.429 & -0.106 & -1.134 \\
\hline & $(0.506)$ & $(0.661)$ & $(0.710)$ \\
\hline \multirow[t]{2}{*}{ QTOB } & 0.218 & -0.200 & $0.706^{*}$ \\
\hline & $(0.250)$ & $(0.436)$ & $(0.396)$ \\
\hline \multirow[t]{2}{*}{ ROA } & -0.00712 & -0.001 & $-0.0349 *$ \\
\hline & $(0.0135)$ & $(0.0197)$ & $(0.0192)$ \\
\hline \multirow[t]{2}{*}{ ENDIV } & -2.356 & -1.729 & -4.986 \\
\hline & $(1.539)$ & $(1.527)$ & $(3.187)$ \\
\hline \multirow[t]{2}{*}{ Caixa } & -0.214 & 1.671 & -1.403 \\
\hline & $(1.684)$ & $(2.661)$ & $(2.755)$ \\
\hline \multirow[t]{2}{*}{$\operatorname{lnMV}$} & 0.149 & 0.694 & 0.126 \\
\hline & $(0.343)$ & $(0.459)$ & $(0.435)$ \\
\hline \multirow[t]{2}{*}{ Constant } & 1.202 & -9.820 & 4.993 \\
\hline & $(7.231)$ & $(8.889)$ & $(10.36)$ \\
\hline Observations & 1,994 & 1,168 & 826 \\
\hline R-squared & 0.005 & 0.015 & 0.021 \\
\hline Number of idfirma & 329 & 244 & 152 \\
\hline
\end{tabular}

Robust standard errors in parentheses

$$
* * * \mathrm{p}<0.01, * * \mathrm{p}<0.05, * \mathrm{p}<0.1
$$


Tabela 18 - Giro dos Fundos - Empresas sem Controlador (ExternosEC e ExternosNEC)

\begin{tabular}{|c|c|c|c|}
\hline VARIÁVEIS & Modelo 1 & Modelo 2 & Modelo 3 \\
\hline \multirow[t]{2}{*}{ ExternosEC } & 0.399 & 1.104 & -4.871 \\
\hline & $(3.161)$ & $(2.348)$ & $(7.760)$ \\
\hline \multirow[t]{2}{*}{ ExternosNEC } & 1.665 & 2.224 & -3.955 \\
\hline & (3.054) & $(2.214)$ & $(7.583)$ \\
\hline \multirow[t]{2}{*}{ tamdir } & 0.135 & 0.239 & 0.102 \\
\hline & $(0.211)$ & $(0.193)$ & $(0.373)$ \\
\hline \multirow[t]{2}{*}{ Dualidade } & -0.346 & -0.274 & -0.419 \\
\hline & $(0.544)$ & $(0.605)$ & (1.163) \\
\hline \multirow[t]{2}{*}{ QTOB } & 0.0944 & -0.742 & $0.783 * *$ \\
\hline & $(0.371)$ & $(0.494)$ & $(0.376)$ \\
\hline \multirow[t]{2}{*}{ ROA } & -0.0128 & -0.00860 & $-0.0412 * *$ \\
\hline & $(0.0167)$ & $(0.0209)$ & $(0.0202)$ \\
\hline \multirow[t]{2}{*}{ ENDIV } & $-4.228 *$ & -2.026 & $-9.872 * * *$ \\
\hline & $(2.157)$ & (1.943) & $(3.248)$ \\
\hline \multirow[t]{2}{*}{ Caixa } & -1.882 & -3.204 & -0.921 \\
\hline & $(1.750)$ & $(2.025)$ & (3.149) \\
\hline \multirow[t]{2}{*}{$\operatorname{lnMV}$} & -0.436 & -0.223 & 0.182 \\
\hline & $(0.398)$ & $(0.546)$ & $(0.634)$ \\
\hline \multirow[t]{2}{*}{ Constant } & 13.09 & 6.418 & 7.763 \\
\hline & $(8.689)$ & $(9.925)$ & $(15.90)$ \\
\hline Observations & 783 & 437 & 346 \\
\hline R-squared & 0.025 & 0.022 & 0.071 \\
\hline Number of idfirma & 158 & 105 & 80 \\
\hline
\end{tabular}

Robust standard errors in parentheses

$$
* * * \mathrm{p}<0.01, * * \mathrm{p}<0.05, * \mathrm{p}<0.1
$$


Tabela 19 - Giro dos Fundos - Empresas com Controlador (ExternosEC e ExternosNEC)

\begin{tabular}{|c|c|c|c|}
\hline VARIÁVEIS & Modelo 1 & Modelo 2 & Modelo 3 \\
\hline \multirow[t]{2}{*}{ ExternosEC } & 0.435 & -1.485 & 0.564 \\
\hline & $(1.749)$ & $(2.278)$ & $(2.971)$ \\
\hline \multirow[t]{2}{*}{ ExternosNEC } & $-3.139 *$ & $-4.477 * *$ & -2.680 \\
\hline & $(1.815)$ & $(2.208)$ & $(3.329)$ \\
\hline \multirow[t]{2}{*}{ tamdir } & -0.0621 & -0.222 & 0.0983 \\
\hline & $(0.132)$ & $(0.190)$ & $(0.200)$ \\
\hline \multirow[t]{2}{*}{ Dualidade } & -0.459 & 0.0493 & -1.972 \\
\hline & $(0.903)$ & $(1.102)$ & $(1.391)$ \\
\hline \multirow[t]{2}{*}{ QTOB } & 0.172 & -0.135 & 0.464 \\
\hline & $(0.356)$ & $(0.511)$ & $(0.736)$ \\
\hline \multirow[t]{2}{*}{ ROA } & -0.00113 & 0.0140 & -0.0107 \\
\hline & $(0.0250)$ & $(0.0323)$ & $(0.0330)$ \\
\hline \multirow[t]{2}{*}{ ENDIV } & -1.083 & 1.388 & -5.881 \\
\hline & $(2.266)$ & $(2.357)$ & $(4.506)$ \\
\hline \multirow[t]{2}{*}{ Caixa } & 0.773 & 2.998 & -1.340 \\
\hline & $(2.142)$ & $(3.373)$ & $(3.612)$ \\
\hline \multirow[t]{2}{*}{$\operatorname{lnMV}$} & 0.628 & $1.148^{* *}$ & 0.367 \\
\hline & $(0.447)$ & $(0.535)$ & $(0.593)$ \\
\hline \multirow[t]{2}{*}{ Constant } & -8.191 & $-17.87^{*}$ & -0.658 \\
\hline & $(9.313)$ & $(10.61)$ & $(13.31)$ \\
\hline Observations & 1,211 & 731 & 480 \\
\hline R-squared & 0.017 & 0.040 & 0.020 \\
\hline Number of idfirma & 242 & 174 & 106 \\
\hline
\end{tabular}

Robust standard errors in parentheses

$$
* * * \mathrm{p}<0.01, * * \mathrm{p}<0.05, * \mathrm{p}<0.1
$$


Tabela 20 - Giro dos Fundos - Todas as Empresas (ExternosEC)

\begin{tabular}{|c|c|c|c|}
\hline VARIÁVEIS & Modelo1 & Modelo 2 & Modelo 3 \\
\hline \multirow[t]{2}{*}{ ExternosEC } & 0.829 & -0.332 & 1.318 \\
\hline & $(0.918)$ & $(1.012)$ & $(1.855)$ \\
\hline \multirow[t]{2}{*}{ tamdir } & 0.0147 & -0.0647 & 0.136 \\
\hline & $(0.107)$ & $(0.124)$ & $(0.182)$ \\
\hline \multirow[t]{2}{*}{ Dualidade } & -0.439 & -0.114 & $-1.266^{*}$ \\
\hline & $(0.503)$ & $(0.659)$ & $(0.692)$ \\
\hline \multirow[t]{2}{*}{ QTOB } & 0.215 & -0.201 & $0.690^{*}$ \\
\hline & $(0.250)$ & $(0.437)$ & $(0.391)$ \\
\hline \multirow[t]{2}{*}{$\mathrm{ROA}$} & -0.00725 & -0.000718 & $-0.0356^{*}$ \\
\hline & $(0.0134)$ & $(0.0196)$ & $(0.0192)$ \\
\hline \multirow[t]{2}{*}{ ENDIV } & -2.365 & -1.751 & -4.869 \\
\hline & $(1.532)$ & $(1.511)$ & $(3.171)$ \\
\hline \multirow[t]{2}{*}{ Caixa } & -0.212 & 1.652 & -1.289 \\
\hline & $(1.683)$ & $(2.662)$ & $(2.708)$ \\
\hline \multirow[t]{2}{*}{$\operatorname{lnMV}$} & 0.151 & 0.695 & 0.124 \\
\hline & $(0.343)$ & $(0.459)$ & $(0.425)$ \\
\hline \multirow[t]{2}{*}{ Constant } & 0.905 & -10.25 & 2.855 \\
\hline & $(7.457)$ & $(9.042)$ & $(10.00)$ \\
\hline Observations & 1,994 & 1,168 & 826 \\
\hline R-squared & 0.005 & 0.015 & 0.020 \\
\hline Number of idfirma & 329 & 244 & 152 \\
\hline
\end{tabular}

Robust standard errors in parentheses

$* * * \mathrm{p}<0.01, * * \mathrm{p}<0.05, * \mathrm{p}<0.1$ 
Tabela 21 - Giro dos Fundos - Empresas sem Controlador (ExternosEC)

\begin{tabular}{|c|c|c|c|}
\hline VARIÁVEIS & Modelo1 & Modelo 2 & Modelo 3 \\
\hline \multirow[t]{2}{*}{ ExternosEC } & -1.083 & -0.907 & -1.413 \\
\hline & $(0.997)$ & $(1.041)$ & $(2.575)$ \\
\hline \multirow[t]{2}{*}{ tamdir } & 0.127 & 0.230 & 0.132 \\
\hline & $(0.215)$ & $(0.198)$ & $(0.405)$ \\
\hline \multirow[t]{2}{*}{ Dualidade } & -0.314 & -0.275 & -0.633 \\
\hline & $(0.534)$ & $(0.599)$ & $(1.085)$ \\
\hline \multirow[t]{2}{*}{ QTOB } & 0.112 & -0.718 & $0.780 * *$ \\
\hline & $(0.373)$ & $(0.507)$ & $(0.372)$ \\
\hline \multirow[t]{2}{*}{ ROA } & -0.0124 & -0.00796 & $-0.0421 * *$ \\
\hline & $(0.0166)$ & $(0.0211)$ & $(0.0210)$ \\
\hline \multirow[t]{2}{*}{ ENDIV } & $-4.183 *$ & -1.914 & $-9.743 * * *$ \\
\hline & $(2.132)$ & $(1.874)$ & $(3.180)$ \\
\hline \multirow[t]{2}{*}{ Caixa } & -1.955 & -3.231 & -0.834 \\
\hline & $(1.734)$ & $(2.030)$ & $(3.020)$ \\
\hline \multirow[t]{2}{*}{$\operatorname{lnMV}$} & -0.455 & -0.248 & 0.136 \\
\hline & $(0.417)$ & $(0.566)$ & $(0.606)$ \\
\hline \multirow[t]{2}{*}{ Constant } & 14.87 & 8.692 & 5.215 \\
\hline & $(9.543)$ & $(11.48)$ & $(14.30)$ \\
\hline Observations & 783 & 437 & 346 \\
\hline R-squared & 0.024 & 0.020 & 0.067 \\
\hline Number of idfirma & 158 & 105 & 80 \\
\hline
\end{tabular}

Robust standard errors in parentheses

$$
* * * \mathrm{p}<0.01, * * \mathrm{p}<0.05, * \mathrm{p}<0.1
$$


Tabela 22 - Giro dos Fundos - Empresas com Controlador (ExternosEC)

\begin{tabular}{|c|c|c|c|}
\hline VARIÁVEIS & Modelo1 & Modelo 2 & Modelo 3 \\
\hline \multirow[t]{2}{*}{ ExternosEC } & $2.779 * *$ & 1.550 & 2.531 \\
\hline & $(1.196)$ & $(1.749)$ & $(1.647)$ \\
\hline \multirow[t]{2}{*}{ tamdir } & -0.0836 & -0.224 & 0.0524 \\
\hline & $(0.130)$ & $(0.190)$ & $(0.181)$ \\
\hline \multirow[t]{2}{*}{ Dualidade } & -0.556 & -0.0119 & -2.147 \\
\hline & $(0.893)$ & $(1.091)$ & $(1.352)$ \\
\hline \multirow[t]{2}{*}{ QTOB } & 0.157 & -0.108 & 0.390 \\
\hline & $(0.358)$ & $(0.530)$ & $(0.719)$ \\
\hline \multirow[t]{2}{*}{ ROA } & -0.00301 & 0.0114 & -0.0102 \\
\hline & $(0.0249)$ & $(0.0323)$ & $(0.0331)$ \\
\hline \multirow[t]{2}{*}{ ENDIV } & -1.247 & 1.027 & -5.872 \\
\hline & $(2.253)$ & $(2.332)$ & $(4.501)$ \\
\hline \multirow[t]{2}{*}{ Caixa } & 0.747 & 2.743 & -1.177 \\
\hline & $(2.151)$ & $(3.407)$ & $(3.559)$ \\
\hline \multirow[t]{2}{*}{$\operatorname{lnMV}$} & 0.612 & $1.086^{* *}$ & 0.396 \\
\hline & $(0.444)$ & $(0.537)$ & $(0.593)$ \\
\hline \multirow[t]{2}{*}{ Constant } & -9.850 & $-19.39 *$ & -2.863 \\
\hline & $(9.436)$ & $(10.70)$ & $(13.22)$ \\
\hline Observations & 1,211 & 731 & 480 \\
\hline R-squared & 0.015 & 0.034 & 0.019 \\
\hline Number of idfirma & 242 & 174 & 106 \\
\hline
\end{tabular}

Robust standard errors in parentheses

$$
* * * \mathrm{p}<0.01, * * \mathrm{p}<0.05, * \mathrm{p}<0.1
$$


O fato de o modelo 3 não apresentar significância na análise pode indicar que justamente esse selo se torna importante quando o gestor mais precisa. Isso pois em caso de empresas de altíssima liquidez para os padrões do mercado brasileiro, o gestor teria mais confiança para segurar o papel por mais tempo, ainda que com indicadores favoráveis ao desmanche da posição, ao saber que poderá se desfazer a posição a qualquer momento no futuro sem um grande spread entre os valores que poderiam ser gerados em caso de baixo volume do papel no mercado.

Os resultados exibidos nas tabelas 20, 21 e 22 não demonstram coeficientes estatisticamente diferentes de zero quando considerados níveis usuais de corte. Quando considerados os resultados das tabelas 23,24 e 25 , no entanto, voltamos a verificar um especial destaque à importância da variável relacionada ao percentual de membros externos no conselho de administração que foram eleitos por minoritários quando a amostra inclui estritamente empresas com controlador definido.

A tabela 25 nos mostra que nessas empresas existe uma relação negativa e significante entre maior concentração desses membros externos e o giro dos fundos o que está alinhado com a hipótese de maior confiabilidade das projeções e, consequentemente, maior confiança por parte dos gestores de fundos, de modo que os papéis dessas empresas encarteirados por esses gestores tendem a permanecer entre os ativos dos mesmos em lugar de oscilar proporcionalmente à posição de cada período. 
Tabela 23 - Giro dos Fundos - Todas as Empresas (ExternosNEC)

\begin{tabular}{|c|c|c|c|}
\hline VARIÁVEIS & Modelo1 & Modelo 2 & Modelo 3 \\
\hline \multirow[t]{2}{*}{ ExternosNEC } & -0.844 & 0.115 & -1.850 \\
\hline & $(0.937)$ & (1.011) & $(1.946)$ \\
\hline \multirow[t]{2}{*}{ tamdir } & 0.0163 & -0.0633 & 0.147 \\
\hline & $(0.107)$ & $(0.124)$ & $(0.181)$ \\
\hline \multirow[t]{2}{*}{ Dualidade } & -0.411 & -0.128 & $-1.181^{*}$ \\
\hline & $(0.502)$ & $(0.658)$ & $(0.695)$ \\
\hline \multirow[t]{2}{*}{ QTOB } & 0.216 & -0.189 & $0.706^{*}$ \\
\hline & $(0.251)$ & $(0.437)$ & $(0.394)$ \\
\hline \multirow[t]{2}{*}{$\mathrm{ROA}$} & -0.00697 & -0.001 & $-0.0352^{*}$ \\
\hline & $(0.0134)$ & $(0.0196)$ & $(0.0192)$ \\
\hline \multirow[t]{2}{*}{ ENDIV } & -2.351 & -1.703 & -4.998 \\
\hline & (1.539) & (1.532) & (3.189) \\
\hline \multirow[t]{2}{*}{ Caixa } & -0.234 & 1.637 & -1.286 \\
\hline & $(1.690)$ & $(2.659)$ & $(2.670)$ \\
\hline \multirow[t]{2}{*}{$\operatorname{lnMV}$} & 0.145 & 0.696 & 0.124 \\
\hline & $(0.346)$ & $(0.462)$ & $(0.432)$ \\
\hline \multirow[t]{2}{*}{ Constant } & 1.739 & -10.54 & 4.140 \\
\hline & (7.433) & $(9.294)$ & $(9.665)$ \\
\hline Observations & 1,994 & 1,168 & 826 \\
\hline R-squared & 0.004 & 0.015 & 0.021 \\
\hline Number of idfirma & 329 & 244 & 152 \\
\hline
\end{tabular}

Robust standard errors in parentheses

$$
* * * \mathrm{p}<0.01, * * \mathrm{p}<0.05, * \mathrm{p}<0.1
$$


Tabela 24 - Giro dos Fundos - Empresas sem Controlador (ExternosNEC)

\begin{tabular}{|c|c|c|c|}
\hline VARIÁVEIS & Modelo1 & Modelo 2 & Modelo 3 \\
\hline \multirow[t]{2}{*}{ ExternosNEC } & 1.297 & 1.271 & 0.845 \\
\hline & $(0.920)$ & $(0.979)$ & $(2.414)$ \\
\hline \multirow[t]{2}{*}{ tamdir } & 0.133 & 0.234 & 0.139 \\
\hline & $(0.216)$ & $(0.195)$ & $(0.409)$ \\
\hline \multirow[t]{2}{*}{ Dualidade } & -0.336 & -0.266 & -0.685 \\
\hline & $(0.536)$ & $(0.603)$ & $(1.112)$ \\
\hline \multirow[t]{2}{*}{ QTOB } & 0.0947 & -0.760 & $0.794 * *$ \\
\hline & $(0.371)$ & $(0.478)$ & $(0.367)$ \\
\hline \multirow[t]{2}{*}{$\mathrm{ROA}$} & -0.0127 & -0.00884 & $-0.0421^{*}$ \\
\hline & $(0.0166)$ & $(0.0208)$ & $(0.0214)$ \\
\hline \multirow[t]{2}{*}{ ENDIV } & $-4.225^{*}$ & -2.079 & $-9.909 * * *$ \\
\hline & $(2.148)$ & $(1.952)$ & $(3.395)$ \\
\hline \multirow[t]{2}{*}{ Caixa } & -1.902 & -3.163 & -0.583 \\
\hline & $(1.711)$ & $(2.034)$ & $(2.800)$ \\
\hline \multirow[t]{2}{*}{$\operatorname{lnMV}$} & -0.441 & -0.220 & 0.129 \\
\hline & $(0.410)$ & $(0.539)$ & $(0.614)$ \\
\hline \multirow[t]{2}{*}{ Constant } & 13.54 & 7.303 & 4.255 \\
\hline & $(9.321)$ & $(11.17)$ & $(13.71)$ \\
\hline Observations & 783 & 437 & 346 \\
\hline R-squared & 0.025 & 0.022 & 0.065 \\
\hline Number of idfirma & 158 & 105 & 80 \\
\hline
\end{tabular}

Robust standard errors in parentheses

$$
* * * \mathrm{p}<0.01, * * \mathrm{p}<0.05, * \mathrm{p}<0.1
$$


Tabela 25 - Giro dos Fundos - Empresas com Controlador (ExternosNEC)

\begin{tabular}{|c|c|c|c|}
\hline VARIÁVEIS & Modelo1 & Modelo 2 & Modelo 3 \\
\hline \multirow[t]{2}{*}{ ExternosNEC } & $-3.533 * * *$ & $-3.215^{*}$ & $-3.200 *$ \\
\hline & $(1.255)$ & $(1.775)$ & $(1.833)$ \\
\hline \multirow[t]{2}{*}{ tamdir } & -0.0601 & -0.217 & 0.107 \\
\hline & $(0.132)$ & $(0.188)$ & $(0.185)$ \\
\hline \multirow[t]{2}{*}{ Dualidade } & -0.443 & 0.00749 & -1.940 \\
\hline & $(0.899)$ & (1.097) & (1.382) \\
\hline \multirow[t]{2}{*}{ QTOB } & 0.170 & -0.111 & 0.470 \\
\hline & $(0.357)$ & $(0.520)$ & $(0.730)$ \\
\hline \multirow[t]{2}{*}{ ROA } & -0.000997 & 0.0135 & -0.0107 \\
\hline & $(0.0250)$ & $(0.0322)$ & $(0.0331)$ \\
\hline \multirow[t]{2}{*}{ ENDIV } & -1.068 & 1.353 & -5.864 \\
\hline & $(2.265)$ & $(2.343)$ & $(4.502)$ \\
\hline \multirow[t]{2}{*}{ Caixa } & 0.758 & 2.969 & -1.400 \\
\hline & $(2.152)$ & $(3.366)$ & $(3.511)$ \\
\hline \multirow[t]{2}{*}{$\operatorname{lnMV}$} & 0.627 & $1.144 * *$ & 0.364 \\
\hline & $(0.448)$ & $(0.535)$ & $(0.593)$ \\
\hline \multirow[t]{2}{*}{ Constant } & -7.805 & $-19.05^{*}$ & -0.135 \\
\hline & $(9.437)$ & $(10.73)$ & $(13.18)$ \\
\hline Observations & 1,211 & 731 & 480 \\
\hline R-squared & 0.017 & 0.039 & 0.020 \\
\hline Number of idfirma & 242 & 174 & 106 \\
\hline
\end{tabular}

Robust standard errors in parentheses

$$
* * * \mathrm{p}<0.01, * * \mathrm{p}<0.05, * \mathrm{p}<0.1
$$

Os resultados encontrados nos modelos 2 e 3 da tabela 25 não nos permitem auferir uma diferença significativa entre empresas com maior ou menor liquidez (acima 
ou abaixo de R 1 bilhão negociados na B3 ao ano). Desse modo pode-se constatar que o resultado encontrado no modelo 1 é robusto e sua maior significância se dá pelo maior volume da amostra que reduz o desvio padrão, não por uma eventual endogenia atribuível à liquidez do papel o que nos permite considerar um nível de significância atribuído ao beta dessa variável de $1 \%$.

\subsection{Modelos com Desafiante}

A partir dos modelos verificados nas seções anteriores, observamos evidências da influência da estrutura de capital sobre a relevância da governa corporativa sobre os indicadores verificados, em linha com a expectativa de o controles serem especialmente relevantes quando há a figura do "controlador" a ser combatida.

A questão que surge subsequentemente é sobre o que traria força aos minoritários nessa empreitada de desafiar o controlador. Para verificar a interferência desse fator aos modelos, separamos empresas com controlador em dois grupos: aquelas que contam com um minoritário intenso capital (o desafiante), e aquelas que contam com uma estrutura de minoritários difusos.

Como desafiante foi classificado o acionista minoritário que detenha ao menos $20 \%$ do capital da empresa esteja essa posição em ações ordinárias ou preferenciais de acordo com a estrutura acionária reportada pela empresa à Comissão de Valores Mobiliários.

As tabelas 26, 27, 28, 29 e 30 mostram os resultados obtidos considerando a segmentação. Como variável relativa à externalidade do conselho foi selecionada a 
ExternosNEC por apresentar os resultados mais robustos das seções anteriores e por estar diretamente relacionado com a força dos minoritários.

A tabela 26 apresenta os modelos relacionados a agressividade com fusões e aquisições. Os modelos de 1 a 3 da tabela utilizam painéis de efeitos fixos, enquanto os modelos 4 e 5 complementam a análise com Poisson. Os modelos 1 e 4 utilizam como variável dependente o número de eventos propostos pela empresa. Os modelos 2 e 5 , apenas o número de eventos concluídos, enquanto o modelo 3 se baseia no volume negociado.

Observa-se que a presença de dualidade entre os cargos de presidente de diretoria e do conselho de administração está relacionado a um menor nível de fusões e aquisições propostas e concluídas pela empresa.

A tabela 27 apresenta a mesma estrutura de modelos da tabela 26, contudo, a amostra utilizada inclui apenas as empresas que contam com as figuras de controlador e desafiante. É possível observar que a significância verificada para a dualidade entre as empresas sem a figura do desafiante, aqui se desfaz e o maior percentual de externos eleitos pelo controlador no conselho mostra-se positiva e estatisticamente significante relacionada ao maior número de eventos propostos ou concluídos pela empresa a nível de $5 \%$ de significância. 
Tabela 26 - Fusões e Aquisições sem Desafiante

\begin{tabular}{|c|c|c|c|c|c|}
\hline VARIÁVEIS & Modelo1 & Modelo 2 & Modelo 3 & Modelo 4 & Modelo 5 \\
\hline \multirow[t]{2}{*}{ ExternosNEC } & 0.0844 & 0.0628 & 0.0664 & 1.003 & 1.006 \\
\hline & $(0.0693)$ & $(0.0737)$ & $(0.406)$ & $(1.068)$ & (1.287) \\
\hline \multirow[t]{2}{*}{ tamdir } & 0.001 & -0.003 & -0.0331 & -0.0357 & -0.0664 \\
\hline & $(0.012)$ & $(0.0126)$ & $(0.074)$ & $(0.081)$ & $(0.085)$ \\
\hline \multirow[t]{2}{*}{ Dualidade } & -0.0208 & -0.0237 & 0.0152 & $-0.747 * *$ & $-0.672 * *$ \\
\hline & $(0.0233)$ & $(0.0232)$ & $(0.151)$ & $(0.305)$ & $(0.321)$ \\
\hline \multirow[t]{2}{*}{ QTOB } & 0.0146 & 0.00264 & 0.117 & -0.521 & -0.697 \\
\hline & $(0.0252)$ & $(0.0246)$ & $(0.143)$ & $(0.484)$ & $(0.503)$ \\
\hline \multirow[t]{2}{*}{ ROA } & 0.001 & 0.001 & 0.004 & $0.062 * * *$ & $0.054 * *$ \\
\hline & $(0.001)$ & $(0.001)$ & $(0.004)$ & $(0.0219)$ & $(0.0220)$ \\
\hline \multirow[t]{2}{*}{ ENDIV } & -0.289 & -0.382 & -0.897 & -1.026 & -1.975 \\
\hline & $(0.265)$ & $(0.261)$ & $(0.709)$ & $(1.462)$ & $(1.350)$ \\
\hline \multirow[t]{2}{*}{ Caixa } & $-0.344^{*}$ & $-0.335^{*}$ & $-1.480 *$ & $-1.431^{*}$ & $-1.551^{* *}$ \\
\hline & $(0.183)$ & $(0.176)$ & $(0.893)$ & $(0.758)$ & $(0.663)$ \\
\hline \multirow[t]{2}{*}{$\operatorname{lnMV}$} & 0.0134 & 0.0211 & 0.115 & 0.111 & 0.236 \\
\hline & $(0.0315)$ & $(0.0302)$ & $(0.126)$ & $(0.299)$ & $(0.296)$ \\
\hline \multirow[t]{2}{*}{ Constant } & -0.0601 & -0.164 & -1.513 & & \\
\hline & $(0.592)$ & $(0.568)$ & $(2.432)$ & & \\
\hline Observations & 731 & 731 & 731 & 232 & 232 \\
\hline R-squared & 0.018 & 0.021 & 0.015 & & \\
\hline Number of idfirma & 172 & 172 & 172 & 39 & 39 \\
\hline
\end{tabular}

Robust standard errors in parentheses

$$
* * * \mathrm{p}<0.01, * * \mathrm{p}<0.05, * \mathrm{p}<0.1
$$


Tabela 27 - Fusões e Aquisições com Desafiante

\begin{tabular}{|c|c|c|c|c|c|}
\hline VARIÁVEIS & Modelo1 & Modelo 2 & Modelo 3 & Modelo 4 & Modelo 5 \\
\hline \multirow[t]{2}{*}{ ExternosNEC } & $0.261 * *$ & $0.287 * *$ & 0.605 & $0.900^{*}$ & $1.068 * *$ \\
\hline & $(0.127)$ & $(0.114)$ & $(0.417)$ & $(0.485)$ & $(0.453)$ \\
\hline \multirow[t]{2}{*}{ tamdir } & $-0.0280^{*}$ & $-0.0255^{*}$ & -0.0505 & $-0.235^{*}$ & -0.217 \\
\hline & $(0.0154)$ & $(0.0152)$ & $(0.0640)$ & $(0.132)$ & $(0.135)$ \\
\hline \multirow[t]{2}{*}{ Dualidade } & 0.0809 & 0.0620 & 0.302 & 0.401 & 0.345 \\
\hline & $(0.0739)$ & $(0.0680)$ & $(0.464)$ & $(0.347)$ & $(0.336)$ \\
\hline \multirow[t]{2}{*}{ QTOB } & 0.0171 & 0.0165 & $0.0904 *$ & -0.112 & -0.118 \\
\hline & $(0.0151)$ & $(0.0144)$ & $(0.0539)$ & $(0.148)$ & $(0.148)$ \\
\hline \multirow[t]{2}{*}{ ROA } & 0.000 & 0.000 & 0.002 & -0.005 & -0.006 \\
\hline & $(0.001)$ & $(0.001)$ & $(0.002)$ & $(0.011)$ & $(0.011)$ \\
\hline \multirow[t]{2}{*}{ ENDIV } & 0.132 & 0.142 & 0.415 & 0.216 & 0.318 \\
\hline & $(0.155)$ & $(0.146)$ & $(0.613)$ & (1.128) & $(1.075)$ \\
\hline \multirow[t]{2}{*}{ Caixa } & -0.0817 & -0.0946 & -0.642 & -0.297 & -0.498 \\
\hline & $(0.124)$ & $(0.122)$ & $(0.571)$ & $(0.914)$ & $(0.858)$ \\
\hline \multirow[t]{2}{*}{$\operatorname{lnMV}$} & $0.0560 * *$ & $0.0562 * *$ & $0.220 * *$ & $0.697 * * *$ & $0.727 * * *$ \\
\hline & $(0.0279)$ & $(0.0275)$ & $(0.0942)$ & $(0.185)$ & $(0.189)$ \\
\hline \multirow[t]{2}{*}{ Constant } & $-0.995^{*}$ & $-1.017 *$ & $-4.160 * *$ & & \\
\hline & $(0.592)$ & $(0.581)$ & (1.937) & & \\
\hline Observations & 853 & 853 & 853 & 350 & 345 \\
\hline R-squared & 0.052 & 0.053 & 0.028 & & \\
\hline Number of idfirma & 185 & 185 & 185 & 64 & 63 \\
\hline
\end{tabular}

Robust standard errors in parentheses

$$
* * * \mathrm{p}<0.01, * * \mathrm{p}<0.05, * \mathrm{p}<0.1
$$

A tabela 28 apresenta os resultados associados a performance. Os modelos 1 e 2 apresentam os resultados associados a empresas sem a figura do desafiante, os modelos 
3 e 4 contam com o minoritário forte. A variável dependente nos modelos 1 e 3 é o valor patrimonial da ação sobre o seu valor de mercado enquanto os modelos 2 e 4 utilizam o lucro por ação como numerador. Nenhum dos modelos mostrou coeficientes significantes estatisticamente aos níveis usuais.

Tabela 28 - Modelos de Performance Segmentados por Desafiantes

\begin{tabular}{|c|c|c|c|c|}
\hline VARIÁVEIS & Modelo1 & Modelo 2 & Modelo 3 & Modelo 4 \\
\hline \multirow[t]{2}{*}{ ExternosNEC } & 0.233 & -0.146 & 0.00144 & 0.00253 \\
\hline & $(0.250)$ & $(0.0902)$ & $(0.217)$ & $(0.0886)$ \\
\hline \multirow[t]{2}{*}{ tamdir } & 0.0187 & $0.0175^{*}$ & -0.0359 & -0.00703 \\
\hline & $(0.0317)$ & $(0.00916)$ & $(0.0378)$ & $(0.0174)$ \\
\hline \multirow[t]{2}{*}{ Dualidade } & 0.115 & -0.00729 & -0.169 & $-0.118^{*}$ \\
\hline & $(0.204)$ & $(0.0703)$ & $(0.103)$ & $(0.0622)$ \\
\hline \multirow[t]{2}{*}{ QTOB } & $-0.752 * *$ & 0.0170 & $-0.389 * * *$ & -0.0186 \\
\hline & $(0.302)$ & $(0.0496)$ & $(0.119)$ & $(0.0462)$ \\
\hline \multirow[t]{2}{*}{$\mathrm{ROA}$} & 0.002 & $0.0163 * * *$ & $0.00781 * *$ & $0.0103 * * *$ \\
\hline & $(0.007)$ & $(0.002)$ & $(0.003)$ & $(0.003)$ \\
\hline \multirow[t]{2}{*}{ ENDIV } & 0.457 & $-0.324 * *$ & 0.0479 & -0.336 \\
\hline & $(0.666)$ & $(0.134)$ & $(0.605)$ & $(0.210)$ \\
\hline \multirow[t]{2}{*}{ Caixa } & -1.085 & 0.0589 & $1.586^{* * *}$ & $0.221 *$ \\
\hline & $(0.690)$ & $(0.208)$ & $(0.465)$ & $(0.125)$ \\
\hline \multirow[t]{2}{*}{$\ln M V$} & $-0.385^{* *}$ & $0.132 * * *$ & $-0.415^{* * *}$ & $0.139 * * *$ \\
\hline & $(0.154)$ & $(0.0398)$ & $(0.149)$ & $(0.0446)$ \\
\hline \multirow[t]{2}{*}{ Constant } & $10.03 * * *$ & $-2.872 * * *$ & $10.07 * * *$ & $-2.849 * * *$ \\
\hline & $(3.024)$ & $(0.832)$ & $(2.936)$ & $(0.879)$ \\
\hline Observations & 403 & 407 & 485 & 484 \\
\hline R-squared & 0.310 & 0.423 & 0.257 & 0.468 \\
\hline Number of idfirma & 112 & 113 & 123 & 123 \\
\hline
\end{tabular}

Robust standard errors in parentheses $* * * \mathrm{p}<0.01, * * \mathrm{p}<0.05, * \mathrm{p}<0.1$ 
Tabela 29 - Giro dos Fundos sem Desafiante

\begin{tabular}{|c|c|c|c|}
\hline VARIÁVEIS & Modelo1 & Modelo 2 & Modelo 3 \\
\hline \multirow[t]{2}{*}{ ExternosNEC } & 0.904 & 1.951 & -0.467 \\
\hline & $(2.004)$ & $(2.515)$ & $(4.130)$ \\
\hline \multirow[t]{2}{*}{ tamdir } & -0.244 & $-1.436^{* *}$ & 0.001 \\
\hline & $(0.338)$ & $(0.665)$ & $(0.294)$ \\
\hline \multirow[t]{2}{*}{ Dualidade } & 1.308 & 2.220 & -3.716 \\
\hline & $(1.479)$ & $(1.580)$ & $(3.419)$ \\
\hline \multirow[t]{2}{*}{ QTOB } & 1.889 & 2.855 & -1.354 \\
\hline & $(1.503)$ & $(1.875)$ & $(1.455)$ \\
\hline \multirow[t]{2}{*}{ ROA } & -0.0502 & -0.056 & 0.006 \\
\hline & $(0.0646)$ & $(0.0924)$ & $(0.0797)$ \\
\hline \multirow[t]{2}{*}{ ENDIV } & -4.822 & 1.512 & -6.201 \\
\hline & $(5.051)$ & $(4.572)$ & $(8.794)$ \\
\hline \multirow[t]{2}{*}{ Caixa } & -3.129 & -2.293 & -6.074 \\
\hline & $(2.667)$ & $(2.565)$ & $(5.667)$ \\
\hline \multirow[t]{2}{*}{$\operatorname{lnMV}$} & -0.376 & -0.150 & -0.563 \\
\hline & $(0.604)$ & $(0.617)$ & $(0.997)$ \\
\hline \multirow[t]{2}{*}{ Constant } & 13.67 & 8.068 & 24.68 \\
\hline & (13.30) & (11.73) & $(23.15)$ \\
\hline Observations & 454 & 224 & 230 \\
\hline R-squared & 0.027 & 0.129 & 0.030 \\
\hline Number of idfirma & 123 & 78 & 55 \\
\hline
\end{tabular}

Robust standard errors in parentheses $* * * \mathrm{p}<0.01, * * \mathrm{p}<0.05, * \mathrm{p}<0.1$

As tabelas 29 e 30 mostram, respectivamente, os dados relativos aos giros dos fundos considerando apenas as empresas sem desafiante e em seguida as empresas com o minoritário forte. O resultado mostra que não há, a níveis usualmente significantes, relações entre o percentual de externos não eleitos pelo controlador e o giro dos fundos 
quando não há a figura do desafiante. Quando consideramos apenas as empresas que contam com essa figura o indicador mostra-se estatisticamente diferente de zero para a amostra completa e reforça-se com empresas com menos de um bilhão por ano em negociação de suas ações na bolsa.

Tabela 30 - Giro dos Fundos com Desafiante

\begin{tabular}{lccc}
\hline VARIÁVEIS & Modelo1 & Modelo 2 & Modelo 3 \\
\hline \multirow{2}{*}{ ExternosNEC } & & & \\
& $-4.473^{* *}$ & $-6.349^{* *}$ & -1.871 \\
tamdir & $(1.767)$ & $(2.952)$ & $(2.420)$ \\
& -0.126 & -0.206 & 0.113 \\
Dualidade & $(0.234)$ & $(0.303)$ & $(0.362)$ \\
& -1.136 & -1.174 & -1.919 \\
QTOB & $(1.214)$ & $(1.588)$ & $(1.895)$ \\
& 0.297 & -0.799 & $2.454 *$ \\
ROA & $(0.680)$ & $(1.012)$ & $(1.307)$ \\
& -0.0317 & -0.0113 & -0.114 \\
ENDIV & $(0.0318)$ & $(0.0297)$ & $(0.115)$ \\
Caixa & -1.507 & 0.735 & -0.985 \\
Nonstant & $(3.326)$ & $(3.910)$ & $(6.945)$ \\
lnMV & 3.672 & $8.909 *$ & -9.557 \\
& $(3.993)$ & $(5.254)$ & $(6.668)$ \\
& 0.861 & 1.166 & 0.932 \\
Number of idfirma & $(0.678)$ & $(0.745)$ & $(0.964)$ \\
& -12.65 & -18.36 & -16.13 \\
& $(13.83)$ & $(15.13)$ & $(19.02)$ \\
& 595 & 386 & 209 \\
& 0.034 & 0.058 & 0.086 \\
& 152 & 113 & 66 \\
\hline
\end{tabular}

Robust standard errors in parentheses

$$
* * * \mathrm{p}<0.01, * * \mathrm{p}<0.05, * \mathrm{p}<0.1
$$




\section{Considerações Finais}

O objetivo principal deste estudo foi verificar estatisticamente se existe uma relação significativa entre governança corporativa e indicadores importantes à vida de uma empresa. Para mensurar utilizamos indicadores relacionados a fusões e aquisições (número de negócios propostos pela empresa, número de eventos concluídos e o volume total das transações concluídas pela empresa no período), indicadores de desempenho (lucro sobre preço e patrimônio líquido sobre preço) e indicadores de persistência do investimento (giro da carteira dos fundos).

O estudo traz para a análise uma nova perspectiva que retoma a essência do estudo de governança que é a segmentação das empresas a serem analisadas de acordo com sua estrutura societária. Empresas que contavam em seu quadro societário com um acionista detentor de mais de $50 \%$ das ações ordinárias foram classificadas como empresas com controlador, as demais foram classificadas como sem controlador definido. Além da figura do controlador foi definida uma nova figura, a do desafiante, responsável por ser a força de equilíbrio ao controlador, é o maior acionista minoritário que detenha, ao menos, $20 \%$ do total de ações.

Essa segmentação vai na origem da governança corporativa uma vez que os problemas e conflitos a serem prevenidos pela estrutura variam se a empresa em questão tem um embate entre controladores e minoritários ou se o foco da atenção está entre acionistas e diretores.

Para essa análise foram utilizadas quatro variáveis usualmente associadas a governança corporativa:

- Percentual de membros externos eleitos pelo controlador no conselho de administração 
- Percentual de membros externos não eleitos pelo controlador no conselho de administração

- Número de membros no conselho de administração

- Dualidade entre presidente do conselho de administração e presidente da diretoria

Das quatro variáveis utilizadas, as relativas a membros externos não eleitos pelo controlador no conselho de administração foi a que teve maior destaque. A figura 2 apresenta um breve resumo dos resultados encontrados.

\begin{tabular}{|c|c|c|c|c|c|c|}
\hline & $\begin{array}{c}\text { Eventos } \\
\text { Ofertados }\end{array}$ & $\begin{array}{c}\text { Eventos } \\
\text { Concluídos }\end{array}$ & Volume & $\begin{array}{c}\text { Book to } \\
\text { Price }\end{array}$ & $\begin{array}{c}\text { Earns to } \\
\text { Price }\end{array}$ & Giro \\
\hline $\begin{array}{c}\text { Todas as } \\
\text { Empresas }\end{array}$ & - & - & - & - & - & - \\
\hline $\begin{array}{c}\text { Sem } \\
\text { Controlador }\end{array}$ & - & - & $-0.480^{*}$ & - & - & - \\
\hline $\begin{array}{c}\text { Controlador sem } \\
\text { Desafiante }\end{array}$ & - & - & - & - & - & $-3.533^{* * *}$ \\
\hline $\begin{array}{c}\text { Controlador e } \\
\text { Desafiante }\end{array}$ & $0.900^{*}$ & $1.068^{* *}$ & - & - & - & $-4.473^{* *}$ \\
\hline \hline
\end{tabular}

Figura 2 - Resumo das relações externos não eleitos pelo controlador e variáveis dependentes

Os resultados encontrados remetem a algumas reflexões interessantes. A primeira delas é que um maior percentual de acionistas externos no conselho de administração associa-se a um maior número de negócios propostos pela empresa, indo na contramão da linha de uso dos instrumentos de governança corporativa para como forma de podar o apetite dos diretores por esses eventos corporativos.

Uma linha que justificaria esse resultado seria a maior confiança verificada por essas empresas pelo mercado de capitais que pode ser verificada pelo menor giro dos papeis das empresas com controlador e desafiante que apresentam maior proporção de membros externos e não-eleitos pelo controlador no conselho de administração. 
Confiança que garante maior acessibilidade aos mercados de boas compras. Essa linha adequa-se aos resultados encontrados nas seções 3.3 e 3.4, pois giro pode viabilizar a emissão de ações para financiar novas compras ao mesmo tempo que a confiança do mercado nos papéis com maior percentual de membros externos e não eleitos pelo controlador, deduzido a partir do menor giro desses papéis, aumenta para papéis com essa característica.

Os resultados encontrados neste estudo assim como a metodologia nele aplicada podem ser de grande valia a outros pesquisadores na área de governança corporativa no futuro, ao lançar luz sobre o caso de segmentação de empresas por estrutura societária e os resultados encontrados.

Este estudo, portanto, não traz a pretensão de fechar uma porta, senão de abrir novas oportunidades a inúmeras questões de pesquisa das quais podemos listar a título de exemplo:

- Quais outras variáveis de governança poderiam ser relevantes aos modelos apresentados?

- Quais outras variáveis poderiam ser impactadas pela governança corporativa tendo em vista a abordagem de segmentação por estrutura societária?

- Seriam essas associações conscientes por parte do mercado, ou decorrentes de algum desvio cognitivo?

Além dessas questões, o campo deverá passar por constantes revisitações associadas a atualizações no ferramental econométrico, mudanças das características de mercado ou ao crescimento na massa de dados. 


\section{Bibliografia}

Agrawal, A., Knoeber, C.R. (1996). Firm performance and mechanisms to control agency problems between managers and shareholders. Journal of Financial and Quantitative Analysis 31, 377-397.

Andrade, G., Mitchell, M., \& Stafford, E. (2001). New evidence and perspectives on mergers. Journal of economic perspectives, 15(2), 103-120.

Andrade, L. P., Salazar, G. T., Calegário, C. L., \& Silva, S. S. (2009). Governança corporativa: uma análise de relação do conselho de administração com o valor de mercado e desempenho das empresas brasileiras. Revista de Administração Mackenzie - RAM, 431.

Baioco, V. G. (2015). Efeito do comitê de auditoria e do conselho fiscal na qualidade da informação contábil no Brasil. Dissertação (Mestrado em Ciências Contábeis) - Universidade do Espírito Santo, Centro de Ciências Jurídicas e Econômicas, 159.

Bebchuk, L. A., Cohen, A., \& Hirst, S. (2017). The agency problems of institutional investors. Journal of Economic Perspectives, 31(3), 89-102.

Bhagat, S., Black, B. (2002). The non-correlation between board independence and long-term firm performance. Journal of Corporation Law 27, 231-273.

Borges, E. C., \& Martelanc, R. (2015). Sorte ou habilidade: uma avaliação dos fundos de investimento no Brasil. Revista de Administração, 50(2), 196-207. 
Brown, R., \& Sarma, N. (2007). CEO overconfidence, CEO dominance and corporate acquisitions. Journal of Economics and business, 59(5), 358-379.

Byrd, J. W., \& Hickman, K. A. (1992). Do outside directors monitor managers?: Evidence from tender offer bids. Journal of financial Economics, 32(2), 195-221.

Carhart, M. M. (1997). On persistence in mutual fund performance. The Journal of finance, 52(1), 57-82.

Chen, H. L., Jegadeesh, N., \& Wermers, R. (2000). The value of active mutual fund management: An examination of the stockholdings and trades of fund managers. Journal of Financial and quantitative Analysis, 35(3), 343-368.

Chevalier, J., \& Ellison, G. (1997). Risk taking by mutual funds as a response to incentives. Journal of Political Economy, 105(6), 1167-1200.

Coles, J. L., Daniel, N. D., \& Naveen, L. (2008). Boards: Does one size fit all?. Journal of financial economics, 87(2), 329-356.

da Silva, E. S., Kayo, E. K., \& Nardi, R. Y. S. (2016). Governança corporativa e criação de valor em aquisições. REGE-Revista de Gestão, 23(3), 222-232.

de Souza, A. A. DESEMPENHO DE FUNDOS DE PENSÃO NO BRASIL SOB A PERSPECTIVA DE INDICADORES FINANCEIROS E ATUARIAIS.

de Oliveira Lima, S. H., Oliveira, F. D., de Aquino Cabral, A. C., dos Santos, S. M., \& Pessoa, M. N. M. (2015). Governança corporativa e desempenho econômico: uma análise dos indicadores de desempenho entre os três níveis do mercado diferenciado da BM\&FBovespa. REGE-Revista de Gestão, 22(2), 187-204. 
de Vilhena, F., \& Camargos, M. (2015). Corporate governance, value creation and economic and financial performance: evidences of brazilian market with panel data, 2005-2011. REGE Revista De Gestão, 22(1), 77-96. Retrieved from http://www.revistas.usp.br/rege/article/view/102624

Fama, E. F., \& French, K. R. (1996). Multifactor explanations of asset pricing anomalies. The journal of finance, 51(1), 55-84.

Fonseca, C. V. C., da Silveira, R. L. F., \& Hiratuka, C. (2016). A relação entre a governança corporativa e a estrutura de capital das empresas brasileiras no período 20002013. Enfoque, 35(2), 35.

Fonseca, N. F.; Bressan, A. A.; Iquiapaza, R. A.; Guerra, J. P. (2007). Análise do Desempenho Recente de Fundos de Investimento no Brasil. Contabilidade Vista \& Revista, v. 18, n. 1, p. 95-116.

Gruber, M. J. (1996). Another puzzle: The growth in actively managed mutual funds. The journal of Hirschman, Albert, 1970, Exit, Voice and Loyalty: Responses to Decline in Firms, Organizations, and States (Harvard University Press, Cambridge, MA).finance, 51(3), 783-810.

Hermalin, B.E., Weisbach, M.S. (1998). Endogenously chosen boards of directors. American Economic Review 88, 96-118.

Hirschman, A. O. (1970). Exit, voice, and loyalty: Responses to decline in firms, organizations, and states (Vol. 25). Harvard university press. 
Holtz, L., Vargas, L. H., Macedo, M. A., \& Bortolon, P. M. (2013). Análise do Tamanho do Conselho de Administração: Evidências no Mercado Brasileiro. Advances in Scientific and Applied Accounting, 321-347.

Huang, J., \& Kisgen, D. J. (2013). Gender and corporate finance: Are male executives overconfident relative to female executives?. Journal of Financial Economics, 108(3), 822-839.

Jensen, M. C., \& Meckling, W. H. (1976). Theory of the firm: Managerial behavior, agency costs and ownership structure. Journal of financial economics, 3(4), 305-360.

Jensen, M. C. (1986). Agency costs of free cash flow, corporate finance, and takeovers. The American economic review, 76(2), 323-329.

Jensen, M. C. (1993). The modern industrial revolution, exit, and the failure of internal control systems, Journal of Finance, 48, 831-880.

Levi, M., Li, K., \& Zhang, F. (2010). Deal or no deal: Hormones and the mergers and acquisitions game. Management Science, 56(9), 1462-1483.

Levi, M., Li, K., \& Zhang, F. (2014). Director gender and mergers and acquisitions. Journal of Corporate Finance, 28, 185-200.

Lubatkin, M. (1983). Mergers and the Performance of the Acquiring Firm. Academy of Management review, 8(2), 218-225.

Malmendier, U., \& Tate, G. (2008). Who makes acquisitions? CEO overconfidence and the market's reaction. Journal of financial Economics, 89(1), 20-43. 
Martynova, M., \& Renneboog, L. (2008). A century of corporate takeovers: What have we learned and where do we stand?. Journal of Banking \& Finance, 32(10), 21482177.

Matos, P. R. F., \& Nave, A. (2012). Fundos de investimento em ações no Brasil: performance e expertise de gestão. Brazilian Business Review, 9(Especial), 1-38.

Matos, P., Correa Silva, W., \& Silva, F. (2015). Há bons gestores de fundos de investimento em ações no Brasil?. Revista Brasileira de Finanças, 13(2).

McCahery, J. A., Sautner, Z., \& Starks, L. T. (2016). Behind the scenes: The corporate governance preferences of institutional investors. The Journal of Finance, 71(6), 2905-2932.

Mehran, H. (1995). Executive compensation structure, ownership, and firm performance. Journal of financial economics, 38(2), 163-184.

Rochman, R. R., \& Eid Jr, W. (2006). Fundos de investimento ativos e passivos no Brasil: comparando e determinando os seus desempenhos. Anais do Encontro Nacional da Associação Nacional de Pós-Graduação e Pesquisa em Administração, Salvador, BA, Brasil, 30 .

Roll, R. (1986). The hubris hypothesis of corporate takeovers. Journal of business, 197-216.

Sharpe, W. F. (1964). Capital asset prices: A theory of market equilibrium under conditions of risk. The journal of finance, 19(3), 425-442. 
Shivdasani, A. (1993). Board composition, ownership structure, and hostile takeovers. Journal of accounting and economics, 16(1-3), 167-198.

Shleifer, A., \& Vishny, R. W. (1997). A survey of corporate governance. The journal of finance, 52(2), 737-783.

Silveira, A., Barros, L. A., \& Famá, R. (2003). Estrutura de Governança e valor das companhias abertas brasileiras. Revista de Administração de Empresas, 50-63. 